\title{
Chronotopes in education: Conventional and dialogic
}

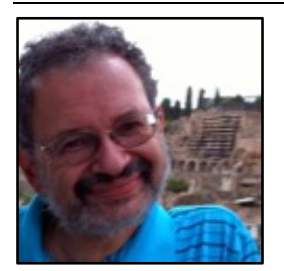

Eugene Matusov

University of Delaware, USA

\begin{abstract}
Bakhtin defines chronotope in his literary dialogic theory as the unity of time and space where events occur. Here, in this conceptual paper, I expand and apply this notion to education, discuss, and illustrate the three major espoused educational chronotopes that I abstracted in my analysis of educational practices around Dialogic Pedagogy. Frist is the Assignment Chronotope based on a type of monologic pedagogy, the most common in conventional, but also in some innovative, schools, focusing on making students arrive at preset curricular endpoints. Second is the Dialogic Provocation Chronotope based on narrowly defined dialogic pedagogy and involving promotion of the students' responsive critical authorship. Third is the Journey Chronotope focusing on promoting the students' self-assignments and self-initiated educational journeys that can propel self-generated critical authorship in a targeted practice (or a network of practices). Educational examples, concerns, and consequences of these chronotopes are considered.
\end{abstract}

Keywords: chronotopes, assignment-based, dialogic provocation, learning journey, critical authorship, responsive authorship, self-generated authorship

Eugene Matusov, Ph.D., DPJ Editor-in-Chief, is a Professor of Education at the University of Delaware, USA. He was born in the Soviet Union. He studied developmental psychology with Soviet researchers working in the Vygotskian paradigm and worked as a schoolteacher before immigrating to the United States. He uses sociocultural and Bakhtinian dialogic approaches to education. Email: ematusov@udel.edu

\section{Acknowledgements}

I want to thank Nermine Elkader, Katherine von Duyke, Mark Smith, Ana Marjanovic-Shane, anonymous peer reviewers for Pedagogies: International Journal, and Dialogic Pedagogy Managing Editors Silviane Barbato and Maria Beatrice Ligorio for their critical feedback and helpful suggestions on the earlier drafts of this paper. My special thanks is to Peter Renshaw and Giuseppe Ritella, the DPJ reviewers who later revealed their identities, for most thoughtful, detailed, critical, and supportive engagement in my manuscript, feedback, and help - I really appreciate this gift to me.

$\cos \cos 80$ 
Many people, who experienced conventional schooling, have a sense of alienation in a grey and dull world of classroom lessons. Yazzie-Mintz (2006) found that $50 \%$ of US high school students are bored EVERY day in their classes. Hart (2006) reported that $82 \%$ of Californian ninth and tenth graders perceived their OVERALL school experiences as "boring or irrelevant" (p. 2). My undergraduate students, future teachers, overwhelmingly reported to me that their best memories of school are of recesses, social events with their friends and classmates (and sometimes even with their teachers), but rarely academic events with the school curricula and their teachers and peers (cf. Sidorkin, 2002). I think the most poetical way this sense is induced is in a famous teacher joke by an unknown author. I read several versions of this joke once titled as "Why Jesus, the Teacher, wept" on the Internet and it is worth to reproduce it in its entirety here:

\section{Why Jesus, the Teacher, wept}

Then Jesus took his disciples up the mountain and gathering them around, he taught them, saying, "Blessed are the poor in spirit, for theirs is the kingdom of heaven. Blessed are the meek, for they shall inherit the earth. Blessed are those that mourn, for they shall be comforted. Blessed are those that hunger and thirst for justice - it shall be given unto them. Blessed are those who are persecuted for my sake, their reward is great in heaven."

Then Peter said: "Do we have to learn all this?"

And Andrew said: "Do we have to write all that down?"

And James said: "Are we having a test on it?"

And John said, "I'm sorry, would you mind repeating that?"

And Andrew said, "John the Baptist's disciples don't have to learn this stuff."

And Matthew said, "Huh?"

And Philip said: "I haven't got any paper."

And Stephen said: "I've lost my pencil."

And Judas said: "Lord, can you photocopy this to save us copying it out?"

And Matthew (again) said: "Please, Jesus, can I go to the toilet?"

Then one of the Pharisees, who was present, asked to see Jesus' lesson plan and enquired, "What are the instructional objectives of this lesson? Is it research-based teaching? What do you expect your students will learn at the end of this lesson? Do you follow the State Standards? How are you going to assess them?"

And Thomas, who had missed the sermon, came to Jesus privately and said, "Did we do anything important today?"

And Jesus, the Teacher, wept.

Unlike Jesus in this joke, teachers in conventional schools usually do not share their mind and heart with their students but rather they "cover curriculum," which is usually preset and described by them and/or other powerful agencies. In many conventional schools, the participants are engaged with not being "here and now" -- they are not "ontologically engaged" (Matusov, 2009a, ch. 11). The teachers and students of conventional schools often bracket their hearts and minds from what goes on in the lesson as if they were educational zombies (Matusov \& Brobst, 2013). But what makes them like that? Can we design a different school and different vision of education where the participants are not so alienated from life in this place? What is responsible for the status quo and what would provoke a possible change? The purpose of this conceptual paper is to address these questions with help of a concept of "chronotope" borrowed from dialogic literary scholar Bakhtin. 
A few scholars (Bloome \& Katz, 1997; Jensen, 2009; Leander \& Sheehy, 2004; Renshaw, 2007) and I (2009) found Bakhtin's literary notion of "chronotope" a promising working concept for addressing these questions. Bakhtin, who was a Russian-Soviet literary theoretician and philosopher of dialogism, defined chronotope as a unity of time and space (chronos and topos in Greek) where events occur, "The chronotope is the place where the knots of narrative are tied and untied" (Bakhtin, 1991, p. 250). Bakhtin used the notion of chronotope to characterize diverse types of historically emerged novels. For example, he characterized the Ancient Greek novel as shaped by the adventure chronotope (i.e., time is abrupt, space is everywhere) while the German romantic novel as the ideological becoming chronotope (i.e., time is personal transformation, space is biographical). As some other educationalists listed above, I am inspired by Bakhtin's chronotopic analysis of historically diverse novels to develop chronotopic analysis of philosophically diverse classrooms (a type of novel $\approx$ a philosophical type of classroom) ${ }^{1}$ while expanding this notion beyond time and space.

I want to use the following example to illustrate a need of the notion of chronotope in education (beyond its use in literary study of novel). In my graduate seminars, I often use an example of closedended schoolish questions, quizzing students, like "2+2 equals what?". I ask my graduate students "2+2 equals what?" suddenly, out of blue, without providing any context or reason for this question. Most of my students predictably and rather quickly reply, "Four." However, if I ask them this same question outside of class: in a café, or on a street or even during research seminars, they do not provide an immediate direct answer but look puzzled asking me, "What do you mean? Why? What's your point?" or just remain silent and puzzled. Even when I tell them about this phenomenon in class and then again ask, "2+2 equals what?", they either tell, "Four", or report (and visually show) their struggle not to say, "Four." What makes them feel that they are forced to answer out of context quizzing questions in the classroom but not outside? What constitutes "classroom"?

In my view, Bakhtin's concept of "chronotope" can be useful to address this and other phenomena in education. Chronotope does not determine the activity but rather provides affordances and limitations for the participants' actions. However, I want to broaden it beyond issues of time and space ${ }^{2}$. The notion of chronotope addresses itself to organization of the classroom focusing on space, time, axiology, participation (forced vs. voluntary), relations, and agency ${ }^{3}$ - that affords (cf. Gibson \& Pick, 2000) a certain type of practice and discourse and while it makes other practices, discourses, axiology, time, space, participation, and relations ${ }^{4}$ more difficult (but never impossible). In different educational chronotopes, events are unfolding differently. I found the concept of "educational chronotope " useful, promising, and attractive because unlike similar concepts like scheme, educational philosophy, model, and so on, it embraces both material and ideological conditions shaping the practice. As Morson and

\footnotetext{
${ }^{1}$ At the same time, so far I do not see usefulness in an association between Bakhtin's particular novelistic chronotopes and educational chronotopes (e.g., "Ancient Greek classroom chronotope").

${ }^{2}$ Incidentally, in his early work before he introduced the notion of "chronotope", borrowed from biology, Bakhtin included the third aspect "axiology" besides "time" and "space" for his analysis of literary work (Bakhtin, 1990). I argue here that even 3 aspects are ${ }^{2}$ Incidentally, in his early work before he introduced the notion of "chronotope", borrowed from biology, Bakhtin included the third aspect "axiology" besides "time" and "space" for his analysis of literary work (Bakhtin, 1990). I argue here that even 3 aspects are not enough and it should also include "participation", "social relations", and "authorial agency". In sum, I argue that educational chronotope should not be reduced to the issue of time-space only.

${ }^{3}$ In conventional schools, the relational aspect of chronotope is often defined by "discipline" or "classroom management, while in dialogic chronotopes it is often defined by "community building" and "democratic self-governance."

${ }^{4}$ In conventional schools, the relational aspect of chronotope is often defined by "discipline" or "classroom management, while in dialogic chronotopes it is often defined by "community building" and "democratic self-governance."

${ }^{5}$ My notion of "educational chronotope" is different from Renshaw's use of the notion of chronotope in his analysis of educational practices mostly from teachers' and students' points of view. In my notion, I focus on pedagogical and educational aspects of the practice while Renshaw focuses on organizational, policy, and managerial aspects from policymakers', educational assessors', and psychologists' points of view (Renshaw, 2013).
} 
Emerson point out, "chronotopes are not so much visibly present in activity as they are the ground for activity" (1990, p. 369).

I argue that the concept of educational chronotope provides new and useful lenses for analysis of educational practices and helps educators better understand what is wrong in conventional school and find new pathways to making schooling an exciting place for learning and teaching. It has both descriptive (in-use) and prescriptive (espoused) power. The concept of chronotope can help us understand, for example, what makes conventional monologic school so boring for many students most of the time (description, in-use chronotope) and what educators may try to do to address this issue and make school learning exciting for many students most of the time (prescription, espoused chronotope). This is mostly a conceptual and not empirical paper and I use reconstructed cases from dialogic pedagogy to illustrate my conceptual points as well as to show how these conceptual points can be useful for analysis and design of educational practices.

Methodologically, I recognize two types of chronotopic analysis: 1) "espoused chronotope" and 2) "in-use chronotope" 6 . Espoused chronotope is a way that the institution and the teacher talk about how their pedagogical practice is organized, i.e., their ideological understanding of their practice. In-use chronotope is how the participants guide their own actions in the practice and how they perceive the practice. White seems to recognize this tension between these two chronotopes when she wrote, "in isolation of their lived experience, and location in time and space, chronotopes become mere categories for external analysis" (White, 2013, p. 166). I agree with White that espoused chronotope - a chronotope outside of the participants' lived experiences - should not be confused with in-use chronotope (or lived chronotope), which may have very different from each other. Also, there can be an interesting and important issue involving possible gaps between how designing participants and observers view an espoused chronotope. However, I respectfully disagree with White's apparent criticism of the espoused chronotope as such - a chronotope in isolation of the participants' lived experiences - as potentially empty and meaningless ${ }^{7}$. A particular espoused chronotope creates affordances or difficulties for emergence of particular in-use chronotopes. Both congruency and gaps between the espoused and inuse chronotopes can be very fruitful for analysis of educational practices. The congruency and gaps may reflect diverse activism by the participants and their mutual relations. In this paper, I primarily focus on typology of espoused chronotopes while raising issues about what kind of in-use chronotopes most likely to emerge in them.

Elsewhere I argue that each type of educational chronotope involves two layers: the ontological and the didactic (Matusov, 2009a, ch. 6). The teacher and the students are usually present simultaneously in the ontological time-space of their classroom where, for example, in a conventional school the students often sit at their desks and the teacher stays at the blackboard during the lesson term limited by the clock of the school timetable. In a conventional classroom, furniture, the position of the participants, sterile environment of the room, and so on are often served to restrict freedom of students' movement: both physical and psychological, focusing them on the teacher, "Classrooms, with their predictable, but not uniform, time schedules, spaces, furniture, artifacts, characters, and inherent goals and purposes arc powerful and readily understood chronotopes" (Renshaw, 2013, p. 58). The immediate physical nature of the classroom environment, affording and limiting the participants' actions, is actively perceived and interpreted by its participants, "Chronotope is not just background or passive context in

\footnotetext{
${ }^{6}$ I create these terms in a similar ways that Argyris \& Schön (1978), scholars of organizational learning, did in their analysis of participants' perception of their practice "espoused theory of practice" and "theory-in-use".

${ }^{7}$ White made her point in a certain context of her grounded discussion and, thus, I am not sure that she sees what I call espoused chronotope only negatively.
} 
which classroom activity occurs, but is active in forming the kinds of characters (teachers and students) and ideologies on which understanding and meaning-making are constructed" (Renshaw, 2013, pp. 5859). The concept of ontology has had a long philosophical and psychological history and often operationalized as personal relevancy, interest, emotional charge, ownership, embodiment, and being in the world. Thus, ontological aspects of chronotope may include diverse time, space, axiology, relational, discursive and participatory frames and scales like gendered, racialized, nationalized, classicized discourses among students and the teacher transcending immediate classroom surroundings. Immediate physical space and time have diverse boundaries and also become a subject of the participants' active and tacit interpretations and mutual interactions: the classroom-lesson, school-term, neighborhoodbiography, country-history, and so on.

Besides the ontological aspect of chronotope, the participants in the classroom find themselves also in the didactic chronotope of their lesson where the participants move through the didactic terrain of the curriculum (i.e., the didactic space) through the process of instruction (i.e., didactic time). When a teacher asks the students at the beginning of the lesson, "Where are we?" he or she usually means not the perceived physical space of their ontological chronotope - i.e., "in the classroom" - but rather the perceived curricular space of the didactic chronotope as some students may reply, e.g., "We've studied addition of fractions." In this educational two-layer chronotope, events occur in the classroom life: questions are answered, students are reprimanded, notes are passed, daydreams are made, grades are distributed, humiliations occur, jokes are cracked, friends are made, tests are prepared, the state standards are addressed (or ignored), and so on. Didactics may or may not be ontological and similarly ontology may or may not be didactic. For example, in a conventional espoused (monologic) chronotope, didactics (e.g., curriculum) and ontology (e.g., social relations) are viewed as independent. However, in an espoused dialogic pedagogy chronotope, at least how I have experienced and understood it, didactics and ontology are viewed as being normatively intertwined: for example, the existing and emerging social relations should become curriculum while curriculum is viewed as reflection and guidance for the participants' social relations. In an espoused dialogic pedagogy, students' engagement in curriculum is viewed to be ontological. When a dialogic pedagogy classroom, a student agrees or disagrees with a position of another person - an immediate participant in the classroom or mediated participant in the classroom by a scholarly text, - the relationship between the student and his/her addressee becomes his/her curriculum while the intellectual content of the discourse will reflect guide this relationship. Moreover, as I will argue below, even in a conventional monologic chronotope, the espoused divide between ontology and didactics cannot be sustainable in practice and it is only ideological in its nature (but still important for the practice!). Lave (1992, April) has introduced notions of "teaching curriculum" (i.e., what the teacher tries to teach) and "learning curriculum" (i.e., what the student actually learns e.g., "math is boring and irrelevant for me"). Although teaching curriculum and teaching instruction (and teaching classroom relations) are often treated as independent by the conventional teacher, the learning curriculum and learning instruction are always integrated.

The espoused divide between didactic and ontological educational chronotopes is the strongest in the espoused (conventional) Assignment-chronotope (A-chronotope) and becomes blurry in espoused Dialogic pedagogy chronotopes (D-chronotopes). In conventional pedagogy, espoused educational chronotope is ontological and didactic, while in dialogic pedagogy, espoused educational chronotope is holistically/inseparably onto-didactic. However, even in dialogic pedagogy, occasionally students may not be ontologically engaged in curriculum, which means that in an in-use dialogic pedagogy chronotope, the ontological and didactic chronotopic aspects may become separated. The opposite can also happen in an in-use conventional chronotope: occasionally, students' engagement in learning material can become ontological. 
Below I consider three major espoused distinctive educational chronotopes of conventional and dialogic innovative schools, with which I am mostly familiar. My major focus will be on Dialogic Pedagogy and discuss pedagogical consequences of them. My choice of the three distinctive educational chronotopes is empirical, reflecting my personal professional development and experimentation as an educator moving from traditional Monologic Pedagogy toward defining Dialogic Pedagogy. The scope of this paper is limited to description of an abstract typology of the educational chronotopes in Dialogic Pedagogy, as certain conceptual abstractions, and does not consider, in any depth, the institutional and/or cultural constraints and affordances for them and complexities of their interaction with each other. Elsewhere (Matusov, 2009a), I analyzed in detail the conventional school chronotope (both espoused and in-use) in its complexity. In this paper, I provide only sketch of espoused conventional schooling ${ }^{8}$ chronotope that serves me for providing important background and as primary dialogic opposition to chronotopes of Dialogic Pedagogy — the latter is my primary focus of this paper.

\section{The espoused conventional Assignment-Chronotope of a conventional school and why it makes academic learning so boring}

Elsewhere (Matusov, 2009a, ch. 6; Matusov \& Brobst, 2013), I came to a conclusion that an educational chronotope of a conventional school can be characterized as an Assignment-Chronotope (or A-chronotope). In this A-chronotope, the ontological aspect of the chronotope (i.e., the physical timespace perceived by the participants) is characterized by the participants' normative expectations about the students' unconditional cooperation to the teacher's demands that the teacher (and the school institution) define as appropriate and educational. This ontological aspect of the espoused A-chronotope shapes the arrangement of the classroom, its furniture, where students sit and where the teacher stays and walks in the classroom, freedom of movement (or the lack of it), control of public communication, management of the attention, and so on in such a way to make this unconditional cooperation easier. At the time, this ontological aspect cannot fully guarantee students' unconditional cooperation. Students actively interpret and respond to this ontological aspect by resistance, compliance, hijacking it for their own purposes, ignoring and so on. All students' responses, strategies, and actions are contextualized by this ontological aspect of the espoused A-chronotope. For example, I have heard that teachers subscribing the A-chronotope complain on "acting out" or "attention angry" students maliciously violating their espoused A-chronotope's insistence on the students' unconditional cooperation. Meanwhile, teachers subscribing to other educational chronotopes may view the actions and behaviors by these students in positive terms as legitimate and good responses to their particular circumstances.

The teacher's unilateral non-negotiable demands expecting students' unconditional cooperation, that I call "assignments," can vary from asking the students to pay attention to something of the teacher's choice, to answer questions, to talk or not to talk, to walk or not to walk, to write or not to write, to solve a problem or to stop working on it, to define topics, and so on. In professional pedagogical literature, the term "assignment" is often referred to the realm of didactics - learning activity work assigned to the students to generate important learning experience. However, I want to broaden this term to totality of all demands, ontological and didactic, by the teacher (like in everyday life's use of this term). Students of conventional schools often perceive school assignments ontologically as some demands unconditionally

\footnotetext{
${ }^{8}$ Peter Renshaw made a very keen observation about my paper, "There is slippage between 'education' 'schooling' and 'classroom' that could be addressed. The title of the paper focusses on education but the critique is about schooling. The conventional chronotope is located in mass schooling with its assumptions about mandated curriculum and conventional roles of teachers and students." In my view, this "slippage" reflects the conventional education that is defined by the chronotope of schooling and classroom. There, the spatial aspect of chronotope is localized and well defined like the temporal aspect (e.g., lesson, semester, school term) or the axiological aspect (e.g., grade). From a dialogic chronotope, education is not bounded by any particular place like school or classroom. In a dialogic educational chronotope, the spatial aspect is not localized but distributed and fuzzy (like all other chronotopic aspects).
} 
imposed on them - "stuff to be done" (rather to have some learning experience important for them). This ontological aspect of the espoused A-chronotope - i.e., physical time-space perceived by the participants where events occur such as classroom-space, lesson-time, teacher's approval-axiology, teacher's classroom management-relations, obedience-participation, - involving students' unconditional cooperation is not unique to a conventional school. It is common with some jobs and some bondages (e.g., military, bureaucracies, slavery, authoritarian patriarchic families). However, usually these institutions do not have the didactic aspect of the espoused A-chronotope (see below). The students' unconditional cooperation in the espoused A-chronotope is achieved through diverse possible means such as (Kohn, 2014):

1) reasoning with the students of why they must surrender their agency to the teacher's arbitrary demands (e.g., because the teacher knows better what is good for the students, because the students will be thankful for this surrender in the future),

2) designing and implementing a system of rewards and punishments (e.g., the "Token Economy", Sidorkin, 2009), and

3) designing and implementing a system of the classroom and school rules, regulations, policies, and norms (tacit or explicit).

The didactic aspect of the espoused A-chronotope involves preset curricular endpoints to be covered (i.e., didactic space), preset instruction (i.e., didactic time), grades and test scores (i.e., didactic axiology), academic motivation to put high efforts in what teacher asks to do (i.e., didactic participation), monologic acceptance of taught (i.e., didactic relations). It can be characterized by the teacher's focus on making the students arrive at the curricular endpoints, preset and pre-designed by the teacher (and/or by the commercial curricular packages and textbooks, by the state standards, by the testing agencies, and so on) by the end of the lesson, the curricular unit, the term, the course, the school, and so on. "By the end of the lesson, the students will be able to master the following skills and demonstrate the following knowledge," - such is the standard statements that National Council of Accreditation of Teacher Education (NCATE, http://www.ncate.org) and the Teaching Standards in many states direct the teachers to have in their syllabus or lesson plan (Taubman, 2009). In the didactic A-chronotope, the teacher sets curricular endpoints in advance, before actual teaching: knowledge and/or skills and/or attitudes that the students have to learn to demonstrate at the end of the lesson to make the educational process institutionally successful and accountable. This teaching objective can be achieved through diverse instructional means. First, it is through conventional instructionism of "direct instruction" (e.g., straightforward scripted lecturing and demonstrating) with its well-defined universal learning trajectory to the preset curricular endpoints. Second, it is through innovative constructivism so-called "discovery learning" with diverse individual pathways to the present curricular endpoint (e.g., hands-on experiences, enriched learning environments, cf. Piaget) and "(co)-construction" with socially diverse pathways to the present curricular endpoints, (question-answer Socratic discussions, scaffolding, "zone of proximal development", cf. Vygotsky), in which learning trajectories are ill-defined, even unique, and negotiated but the curricular endpoints are still preset ${ }^{9}$. The students' success or failure in achievement of the preset curricular endpoints is defined by formal and informal tests, quizzes, and exams usually administered by the teacher or a testing agency. Informal testing involves students' replies to the teacher's or textbook's questions or their performance on classroom assignments that are often graded by the teacher. The recent well-meaning educational policies like the No Child Left Behind by President Bush or the Race to

\footnotetext{
${ }^{9}$ In this paper, I limit myself to an analysis of mostly conventional espoused A-chronotope and not of innovative constructivist ones, based on exploitation of student authorial agency to force the student to arrive at the preset curricular endpoints. I will briefly discuss Progressive education that, in my view, based on this constructivist espoused A-chronotope at the end of paper. The analysis of innovative constructivist A-chronotopes is needed.
} 
the Top by President Obama provide support for the didactic aspect of the espoused A-chronotope (Matusov, 2011b).

There is no transactional relationship - i.e., relations that mutually constitute each other (Altman \& Rogoff, 1987) - between didactic and ontological aspects of the espoused conventional A-chronotope (Matusov, 2009a, ch. 6). This means that the classroom ontology does not constitute the didactics and the didactics does not constitute the classroom ontology in the espoused conventional A-chronotope. In a conventional school A-chronotope, the teacher-students social relationship (i.e., ontology) is not rooted in the studied curriculum (i.e., didactics). And the studied curriculum (i.e., didactics) is not rooted in the teacher-students social relations (i.e., ontology) (Lampert, 2001). Thus, by analyzing the classroom social relations among the participants, one can't find out if they study fraction addition or the history of Mesopotamia. Similarly, an observer of the didactic chronotope alone won't see social relations in the classroom specific to the taught curriculum (e.g., whether the education is forced or voluntary for the students). As soon as the students' unconditional cooperation with the teacher's arbitrary demands is achieved - the unilateral classroom order is established - anything can be taught. Similarly, the content and instruction are independent of the classroom order in the espoused A-chronotope. The firewall separation and the great divide of the ontology and didactics in the espoused A-chronotope is probably the most acute reason of why teachers and students feel so alienated in the classroom (Matusov, 2009a; M. P. Smith, 2010; Whitson, 2007).

However, despite being ideologically independent of its content, in practice (in-use) there is a complex interactional relationship (Altman \& Rogoff, 1987) between the ontological and the didactic aspects of the espoused conventional A-chronotope to support each other. For example, through test outcomes and the teacher's surveillance of the students' work on the assignments, the ontological and didactic aspects of the espoused A-chronotope interact with each other: the tests' outcomes provide assessment of the didactic success and also measurement of a student's cooperation and activation of the reward-punishment system. I asked my teaching colleague of why she administers so many tests in her class and she replied to me that she does so to ensure students' attention during her lecture and students' reading the assigned literature. At the same time, the student's unconditional cooperation with the teacher's demands is supposed to ensure the student's high performance on the test. There is even a suspicion among the general public and politicians, supported by ethnographic research, that many conventional teachers prioritize the students' unconditional cooperation (i.e., obedience) over achieving the curricular endpoints -so called "defensive teaching" (Jackson, 1968; Kennedy, 2005; Matusov, 2009a; Waller, 1932), "...what might on the surface appear to be untrained teaching was in fact the active response of some of the best teachers observed as they confronted the organization which rewarded their ability to control students more than their ability to 'really teach"' (McNeil, 1986, p. 211). The recent Standard movements (see NCATE, http://www.ncate.org/public/standards.asp) and the No Child Left Behind school policies (http://www2.ed.gov/admins/lead/account/saa.html) reflect this concern. In the espoused A-chronotope, the students' unconditional cooperation AND setting and achieving the curricular endpoints by the teacher are assumed as possible and desirable. Let's consider these issues critically.

\section{Is the espoused conventional A-chronotope ecologically possible?}

Can students unconditionally cooperate with the teachers' arbitrary demands and really forget or postpone their own needs, interests, desires, questions, problems, inquiries, and agency for K-16 school $^{10}$, hour after hour, day after day, year after year in the classrooms as the espoused conventional A-chronotope requires from them? Is it humanly possible? There is rather little research done in this area

\footnotetext{
${ }^{10}$ This is at least 17 years in a row for many students or even more for preschool, college, and even graduate school.
} 
except that many students lose their interests in academic subjects while progressing in school (Brandes, 1996). We do not know to what extent are emotional, intellectual, relational, personal, collective current and future well-being of the students (and, to a lesser degree, of teachers) impacted by the delegitimatization of the following processes in conventional school:

1) genuine dialogic meaning making of academic issues,

2) students' setting their own goals,

3) their self-actualization,

4) collaboration,

5) interpersonal problem solving initiated and completed by the students,

6) the students' ownership for engaged activities,

7) the students' curricular and thematic initiatives, and

8) their creativity and originality, and so on... - in short, student "authorial agency" (Matusov, 2011a).

Clearly the ontological chronotope of unconditional cooperation makes all these processes illegitimate and difficult (but, probably, never fully impossible). There is evidence that students' perception of conventional school heavily involves feelings of being tired and bored (DePalma, Matusov, \& Smith, 2009; Hart, 2006; Jackson, 1968; Waller, 1932; Yazzie-Mintz, 2006), which can be symptoms for this ecological impossibility for the espoused A-chronotope. Majority of students of conventional schools look forward to times when school is over or canceled (Matusov, 2009a).

In the very extreme case, when the ontological regime of unconditional cooperation with the authority's arbitrary demands is highly totalized, people seem to die because of some kind of breakdown in their immune system (Bettelheim, 1960). Scholars of concentration camps report that attempts by the totalitarian authority to "re-educate" their dissident and independently minded citizens to obey unconditionally, when successful, often led the "re-educated" people to become zombie-like and quickly die from some benign causes (Bettelheim, 1960; Kotek \& Rigoulot, 2000). Of course, the goal of conventional school is not to break students in total submission, robbing them of any subjectivity as in concentration camps of totalitarian regimes, - the educational conventional A-chronotope involves some degree of negotiation of the teacher-students cooperation, leeway for students' autonomy, and a lack of the totalizing surveillance ${ }^{11}$ over the students, -- but the parallels and their limitations are worth studying, in my view (Matusov, 2011a).

Besides the issue of its ill effects on the students (and teachers), there is another ecological question of the sustainability of the ontological regime of the students' unconditional cooperation with the espoused conventional A-chronotope. Can it be institutionally sustained more or less successfully? Sociological and ethnographic research shows that the ontological regime of the espoused conventional A-chronotope is especially troublesome for minority and working class students through their resistance, disruption, disengagement, violence, and truancy (Eckert, 1989; Willis, 1981) probably because these social groups have overall less benefit from conventional monologic schools for their socioeconomic existence (Labaree, 1997; Varenne \& McDermott, 1998). Sidorkin (2002) has claimed that overall sustainability of the unilateral regime of the espoused A-chronotope of conventional schools has deteriorated and is under assault. He cites statistics of increasing pedagogical violence in all schools caused by students' non-cooperation with teachers' and school demands (i.e., symbolic, relational, emotional, institutional, and physical teacher-students and peers' violence) and teachers' growing dissatisfaction and attrition. He explains this phenomenon by the school's growing impotence in using

\footnotetext{
11 Although, see the recent scandal over school surveillance of students' homes using web cameras on the school laptops distributed among the students http://www.huffingtonpost.com/2010/02/18/harriton-high-school-spie n 467491.html
} 
previously legitimate (and legal) repressive measures, including school expulsion, corporal punishment, psychological humiliation, and so on. Sidorkin claims that the sting of such repression was enhanced by the school's exclusive nature, in an era before schooling became compulsory, when attendance in schools was a desired social privilege that almost automatically guaranteed good well-paid jobs and social stability for well-to-do social classes.

Now let me turn to the issue of the ecological (im)possibility of the didactic aspect of the espoused conventional A-chronotope. Can the curricular endpoints, preset by the teacher, be achieved in a predictable fashion through some good instruction and organization of the classroom? Although this question goes beyond the popular issues of whether achievement gaps in tests among social groups and individual students can be eliminated in principle, the issue of the achievement gap is still relevant for this inquiry.

Several sociocultural scholars have claimed that learning (and its "outcomes") cannot be designed and controlled by teaching because learning is an aspect and by-product of any activity (Lave, 1992, April; Matusov, 2009a; Wenger, 1998). People always learn, but what they learn remains an open question. However, they learn different things from each other and from what the teacher expects them to learn. Learning cannot be socially engineered in a predictable guaranteed fashion through instruction, channeling conditions, or organizing experiences (Lobok, 2001). Scholars of the Bakhtinian dialogic approach argue that the learning process, like understanding and meaning making, is unique to the individual and his or her experiences (Matusov, 2011a; Morson, 2011). Also, as far as I know there is no developmental psychological theory predicting guaranteed learning in all students of the same curriculum. Empirical evidence for predictable achievement of the preset curricular endpoints is mixed. Even when in a particular classroom all students could pass some test, the validity, authenticity, and depth of this learning outcomes is often in question (Varenne \& McDermott, 1998). Two questions remain: 1) whether any instructional success remains uncertain and probabilistic in its nature - probabilistic in a broad, nonmathematical, sense (Lobok, 2001; Matusov, 2009a) and 2) whether "a learning outcome known in advance" is a misnomer fabricated by educational tests - can any two people know the exactly same thing and be able to master the exactly same thing in principle (are people replaceable with regard to knowledge and skills)?

The espoused conventional A-chronotope is based on an untested assumption that knowledge and skills (and attitudes and dispositions) are "immutable and combinable mobiles" (Latour, 1987, p. 227):

1) across people - different people can enact "the same" knowledge and "the same" skills and

2) across practices and situations - diverse practices consist of a set of "the same basic and essential skills" that can be triggered, combined, and applied based on certain conditions as needed (and learned separately in school).

The sociocultural empirical research in diverse fields of the social sciences suggests that knowledge and skills cannot be separated from people and situations (Hutchins, 1995; Latour, 1987; Wenger, 1998). People may not be containers of self-sufficient, standardized, independent knowledge and skill; but rather, as I suspect, they seem to "author" their unique knowledge and skills as they participate in their practices. From this point of view, only the recognition of uniqueness of people's knowledge and skill defines them as human beings with personal responsibility and creativity within their personal deeds. If there are practices and social relations (like some jobs in the economy) for which people are replaceable, the issue emerges how much these jobs are for humans and, thus, humane, and whether these jobs might not be replaced by "smart" machines (now or in future) (Zhao, 2009). Thus, if the school focuses on 
making students mutually replaceable with the same knowledge and skills, is the goal of school education to produce machine-like people (i.e., human zombie-robots)?!

The espoused conventional A-chronotope seems to be based on another untested assumption that practices and people's participations in them are assemblies of fundamentally simple, standard, selfcontained bits of knowledge and skill detached and always detachable from their goals, values, and uses. According to this untested technological assumption about the nature of human skills and knowledge, the diverse practices and complex participations can be disassembled to simple fundamental bits of knowledge and skill that can be taught in school. For example, since skillful bicycle riding requires balancing the bike, this skill detached from biking practice has to be learned in school as precursor of riding a bike. Or in a more school related example, since fluent reading of an alphabetic based text requires phonetic and phonemic awareness, this awareness has to be taught in school as a precursor of reading. In this paradigm, to read fluently means to assemble unrelated standardized bits of skills and knowledge about the linguistic structure. However, as far as I know, there is no empirical evidence that practices and participations are assemblies of self-contained bits of knowledge and skill. Balancing on a bike detached from biking might not be a precursor of riding a bike but its by-product transitionally emerging from learning to ride. Similarly, phonetic and phonemic awareness might not be a precursor of reading but a transactional by-product of it (Matusov, 2011a; F. Smith, 1985). For the fact that there is a strong correlation between, for example, phonetic-phonemic awareness and fluency of reading does not mean that this awareness is a causal relationship with the awareness being the cause of reading (i.e., socalled "correlation fallacy" to assume a causal link solely from correlation evidence). At least, we have some evidence coming from sociocultural research that phonemic awareness can be a byproduct rather than a precursor of literacy (Scribner \& Cole, 1981). The metaphor of "immutable and combinable mobile" regarding to self-contained and detached knowledge and skill can be simply wrong (Matusov, 2011a) and the so-called problem of "transfer" - the students cannot apply what they learn in school -- is one of the major symptoms of the false assumption on which the educational Assignment Chronotope is based (Greeno, 1997).

Thus, despite its ideological claims, the espoused conventional A-chronotope is never fully feasible either for students or for teachers. Sociocultural microanalysis may show that students' and teachers' agencies always transcend the preset nature of the curricula; students' cooperation is never fully unconditional; dialogic meaning making and negotiation penetrate the espoused conventional Achronotope, although often in rather distorted forms. No two students nor two teachers in the espoused conventional A-chronotope ${ }^{12}$ are exactly alike - they enact it differently. Elsewhere I have discussed three major student responses to the espoused conventional A-Chronotope: resistance, smuggling, and conformity and I argued that even conformity is a rather complex phenomenon involving student authorial agency (Matusov, 2011a). In addition, a mixture of educational chronotopes can be in place. Discussion and study of diversities and complexities of the espoused A-chronotope in-action is definitely worth of further empirical research beyond this paper.

\footnotetext{
${ }^{12}$ Some of the reviewers criticized previous drafts of my paper for "stark binaries" and "vilification/valorization" with regard to description of the A-chronotope. I feel both fairness and unfairness in this observation. I agree that the issue is complex but I also argue that this complexity does not necessary undermine legitimacy for "stark binaries." Let me provide an illustration (not an analogy) to clarify my point. I agree that slave-owners were very diverse in their relations to their slaves varying from pure sadism to patronizing to human sympathy to even truly romantic relations. This fact of diversity and complexity of slavery, however, does not preclude its critics from passing legitimate judgments of "stark binaries" and "vilification/valorization" of slavery (in its opposition to freedom and democracy for all). Sometimes stark binaries and vilification/valorization are very legitimate in my view, and we should avoid decontextualized and unconditional condemnation of these, at times, useful analytical tools. Similarly, excessive monologism of conventional pedagogy can be rather complex and contradictory but this should not necessary precludes us from passing a binary, yes, binary and dichotomous, judgment on it. In my view, a fashionable, total, and decontextualized ban on "stark binaries" and dichotomies can be as detrimental as unconditional and total acceptance of them (and ironically, such condemnation is, in itself, actually the same "stark binary").
} 


\section{Is the espoused conventional A-chronotope educationally desirable?}

Let's assume that conventional schools based on the educational Assignment-Chronotope do the excellent job of teaching ALL students how to acquire standardized knowledge and skills as measured on national and international standardized tests (i.e., espoused conventional A-Chronotope's definition of educational success). Let's imagine that educationalist neuroscientists have managed to crack the brain's learning code and develop research-based instruction that works for all students (cf. Asimov, 1959). As a result, all of the students have passed with excellence, super challenging high-stakes state and national standard-based tests ${ }^{13}$ - no child, no student, is truly left behind. Do we want to live in this utopia?

I am not interested here, within the limited space of the paper, in a detailed discussion of the economic, social, and political consequences of this A-chronotope "paradise" (for instance, if everyone does so well on tests and assignments - who will deliver pizza and who will remain unemployed to serve the economic well-being of the society?!, see Matusov, 2008; Sidorkin, 2009). Rather, I am interested in discussion of its educational consequences. As I have alluded above, the educational conventional Achronotope does not intend to teach self-actualization, initiative, self-assignment, assignment to others, goal defining and prioritization, independent problem defining and problem solving of social conflicts, democracy, collaboration, teamwork, self-determination, responsibility, creativity, initiation and participation in complex enterprises, love of learning, self-directed learning, unique voice in practices, etc. (i.e. what Greenberg called "real basics of education", see Greenberg, 1992b). It does not support and enrich human agency, and as one student says, "it sucks life out of me" (DePalma, et al., 2009). "Everyone is busily grading, assessing, evaluating, ranking, rating, and of course preparing for the next test. Every school will be graded on a scale of A-F . . . [A]ccountability destroys not only the joy of learning, but learning itself" (Ravitch, 2007, February 25). In this sense, conventional schools fail all students those who institutionally succeed - usually, middle and upper class students - and those who institutionally fail - usually working class and minority students (but in different ways and with different institutional and economic consequences) (Matusov, 2011b; Varenne \& McDermott, 1998).

The espoused conventional A-chronotope pushed to its limits creates ideal interchangeable and replaceable human machine, human zombie-robots (for the economy) that do not know what to do with their freedom when this freedom is offered or achieved (Fromm, 1969). When knowledge and skills are not rooted in people's immediate desires, interests and needs (their ontology), which is often bracketed by conventional monologic education, knowledge and skills become decontextualized (Lave, 1988). Separation of knowledge and skills from people's ontology in the espoused A-chronotope generates the so-called "transfer problem" - the students may perform well on tests but poorly in the flow of practices where the "learned" knowledge and skills are required (Beach, 1999; Hunter, 1971; Parker, 2001). Of course, one can take an issue that the conventional monologic school actually fits current economic needs. The current economy in its huge part might not greatly need educational outcomes and processes involving people's agency, creativity, self-actualization, and so on. Only a small elite might need these agency-based learning (cf. estimation of percentage of "creative jobs" needed by modern economy, less then $20 \%$, Reich, 1992, 2001). Still from an educational perspective (that I will fully develop below), the desirability of the educational A-chronotope remains questionable as well as its incessant, wide-spread, and institutional omnipotence. Should people spend 17 years in their schools to learn how to behave like machines?!

\footnotetext{
${ }^{13}$ Although, how would educators assure "super challenging" quality of the tests, test criteria, and testing benchmarks when everybody succeeds?! Usually tests are normalized in such a way that making it succeed by too many students "indicates" to the test designers that the test is "not challenging enough" which often leads to revision of the tests. Let me leave this question to the brain learning scientists and the test designers and let's stretch out our imagination in the educational utopia paradise of the Achronotope.
} 


\section{The espoused and in-use Dialogic Provocation and Journey Chronotopes of dialogic pedagogy}

Here I focus on discussion of alternative educational chronotopes that have emerged in a dialogic pedagogy practice. Dialogic pedagogy (e.g., Adler, 1982; Bibler, 2009; Fecho, 2011; Freire, 1986; Matusov, 2009a; Mercer \& Littleton, 2007; Nystrand, 1997; Plato \& Bluck, 1961; Sidorkin, 1999; Solomadin \& Kurganov, 2009; Wegerif, 2007) focuses on promoting students' critical authorship in the targeted practices they learn. I define critical authorship as such contribution to an activity that transcends ready-made norms and limitations - achieving transcendence that defines its own quality, is recognized by the self and relevant others, and is taken responsibly by the author (Matusov, 2011a). For example, a student's reply to the teacher's question, $2+2=4$ can be authored - a critically authored reply to the problem set by the teacher - only if a student knows how to evaluate and justify this answer as good or bad in diverse contexts and, thus, to be responsible for his or her answer (regardless of the correctness of this evaluation or justification by itself ${ }^{14}$ ). So, from this perspective, some replies by students might be non-authored because the student cannot evaluate these replies. Or a student may author an answer but not critically - when the student does not involve the answer in a critical discourse (i.e., "internally persuasive discourse", see Bakhtin, 1991; Matusov, 2007; Matusov \& von Duyke, 2010) and hence the student is not responsible for his or her own transcendence - i.e., cannot answer for it ${ }^{15}$. Strictly speaking, probably all contributions are authored to some degree, because all replies can be justified even in the worst-case scenario: e.g., "My answer is just a random guess forced by the teacher and her threat of punishment if I keep silent." But, I argue, this ontological authorship has a very low didactic degree by being not very critical and/or academic in the subject matter. In the espoused conventional A-chronotope, described above, the degree of students' educational authorship is usually very low. In case of student compliance, the student uncritically accepts authoritative discourse. In case of creative resistance, the student's high degree critical authorship is often non-academic. In case, when the student smuggles his/her interests in the classroom, these learning interests are often not supported and not guided by the teacher. In contrast, critical educational authorship is achieved through students' ownership and responsibility ${ }^{16}$ for their own contributions and actions.

Elsewhere, I argued that narrowly defined dialogic pedagogy values the responsive critical authorship while polyphonic pedagogy ${ }^{17}$ values the self-generated critical authorship (Matusov, 2011a; Matusov \& Brobst, 2013). The responsive critical authorship is the critical authorship in response to somebody else's provocation. For example, students can be very creative, critical, and have a high degree of ownership for their work developed by them in response to their teacher's (or other students')

\footnotetext{
${ }^{14}$ For example, a first grader justified $2+2=4$ by drawing vertical lines $\|+\|=\mid I I$ and claiming that this mediation by the vertical lines can be done for any addition of any two and two objects. This evaluation was contested by other children (i.e., adding 200 and 200) and by me (adding two friends and two friends) (Matusov, 2009a). It does not matter that the first grader's evaluation of mathematical equation did not survive the test because she and other participants were engaged in the authentic math discourse through deep understanding. The student was a true author of her math reasoning.

${ }^{15}$ The German movie "The wave" (2008), a dramatization of real events occurring in Palo Alto, USA, in the late sixties (Jones, 1972), shows how a social studies teacher promotes a high degree of non-critical authorship in his students by creating a neo-Nazi organization. This raises an issue that authorship, agency, creativity, and participatory socialization alone, without critical dialogue of internally persuasive discourse in which everything is "dialogically tested and forever testable" (Morson, 2004, p. 319), cannot completely define education.

${ }^{16}$ In conventional education, student responsibility is often understood as acting in according to the societal norms or even the teacher's demands and desires. Here, I understand student responsibility as a student's own act of defining good and bad and replying to challenges by others and self about meaning, values, and intentions of his/her own actions (Bakhtin, 1993).

${ }^{17}$ I call this pedagogy "polyphonic" (Matusov, 2009a) adapting Morson and Emerson's definition of Bakhtin's notion of polyphony as, "'two closely related criteria are constitutive of polyphony: 1) a dialogic sense of truth and 2) a special position [by the teacher and the students] of the necessity for [promoting] this sense of truth [in the classroom community]. In fact, these two criteria are aspects of the same phenomenon, the polyphonic [classroom's] 'form-shaping ideology'. They can be separated only for purposes of analysis" (Morson \& Emerson, 1990, p. 234).
} 
dialogic provocations: the teacher's open-ended questions, a shown video, a demonstration, the students' reflection-provoking experiences organized by the teacher, by the students' own learning experiences, or by peers. The teacher's dialogic provocation differs from the teacher's assignment of A-Chronotope, described above, because the teaching provocation is aimed at revealing and provoking the students' position, thinking, feeling, ideas, perception, creativity, collaboration, and "situational interest" (see, Hidi \& Renninger, 2006) not fully known and predicted by the teacher - i.e., critical authorship, - rather than at making the student arrive to some curricular endpoint preset by the teacher. I call that the student's responsive critical authorship because it emerges in response to the teacher's, experiences', or peers' provocation. It is not self-initiated, self-generated by the student. Although students may be very creative and responsible for their contributions, they do not produce their creative critical contributions on their own, without or outside of learning activities designed by the teacher. Dialogic pedagogy (in its narrow sense) values promotion of responsive critical voice in the students, while polyphonic pedagogy values promotion of self-generated critical voice in the students. In my view, narrow dialogic pedagogy is based on Dialogic Provocation Chronotope (DP-chronotope) in education; while polyphonic pedagogy is based on Journey Chronotope (J-chronotope) in education. In both DP- and J-Chronotopes what students learn is not expected to be known by the teacher and the students themselves prior to this learning.

The self-generated critical authorship is characterized by the students' (individual and collective) strategic goal-defining, self-determination, and their short- and/or long-term commitment to the learning practice through their self-initiated assignments - i.e., students' short-term commitments to their selfinitiated interests, inquiries, and projects, - and the student's curricular transformative self-initiated learning journeys - i.e., students' long-term commitments to their self-initiated interests, inquiries, and projects (cf. Renshaw, 2007). In polyphonic pedagogy, students are not creative, active, critical, and responsible only in response to the assignments set by others (usually by the teacher); but also they are creative, active, critical, and responsible for setting new assignments for themselves alone or in collaboration with others (e.g., the classmates, the teachers, the parents). In contrast to the responsive critical authorship, the self-generated critical authorship transforms and defines who the students are through the learning practice in relationship to themselves and other people - i.e., people who self-assign activities and who set themselves on long journeys. The self-generated authorship creates in participants new desires, new interests (i.e., "personal interests" in contrast to "situational interests", see Alexander, 2005), and new needs to do something new. In polyphonic dialogic pedagogy, the participants become new dialogic agents. The main role of the teacher in the espoused J-Chronotope is to support students' self-assignments and journey. Currently, I see four main aspects of this support:

a) making unsolicited and solicited suggestions for what the student may do or try (i.e., alternative ideas and experiences),

b) providing guidance by engaging in critical dialogue when and only when asked for this guidance by the student,

c) providing "community behind" to strengthen the student's voice by affirmation and validation of the student's contributions (Matusov, 2009a; Mitra, 2013), and

d) providing a rich learning environment for the student's exploration and exposure.

However, more investigation of the teacher's legitimate role in the espoused J-Chronotope is needed.

The demarcation between the responsive critical authorship and the self-generated critical authorship is relative and not absolute. Any responsive authorship involves an aspect of the selfgenerated authorship because it involves a student's initiative that transcends and is not defined by the 
teacher's assignment but is rather provoked and encouraged by it. Similarly, any self-generated authorship is inherently responsive - being social by its nature, any self-generated human authorship responds to and addresses other people, it takes certain things for granted and transforms other things: creativity and innovation never start from scratch (Bakhtin, 1986). People's self-initiated contributions are always located in a framework of "bigger assignments" that they accept, undertake and expand from and in response to other people. Thus, the self-generated authorship is deeply responsive in its nature and it distinguishes itself from the responsive authorship by a degree, which however makes a qualitative difference when the student's initiative expends and even negates the parameters of the teacher's assignment itself so the latter stops shaping the former. Even more, I argue that sometimes the selfgenerated authorship can grow out of the responsive authorship but, this is, probably, only one out of many possible developmental trajectories for the emergence of the self-generated authorship. The following example illustrates this possibility of the J-chronotope, emerging from the students' responsive critical authorship, the DP-chronotope.

Elsewhere my colleagues and I (see, Rogoff, Bartlett, \& Goodman Turkanis, 2001) described an innovative collaborative public elementary school running as a parents-teacher cooperative. Primarily, I was a parent in this school. My son attended $1^{\text {st }}$ and $2^{\text {nd }}$ grades there. In my chapter (Matusov, 2001), I described how as a parent volunteer (named "co-oper" in the school) responsible for the classroom math activities once a week for 3 hours, I was learning how to participate in an adult community of learners. Here I want to expand and reconstruct the case as a participant in more details than I described in that chapter (and supported by fieldnotes at time).

The event started (at least for me) from a parents-teacher meeting. At this meeting, a disagreement emerged among parents. At the meeting, some of the parents wanted to shift to a more traditional direct instruction based on the espoused conventional A-chronotope out of pragmatic reasons that certain subjects and/or curricular topics cannot be taught in a constructivist way through discovery and hands-on learning. As an example of such curricular topics that require conventional teaching based on the espoused conventional A-chronotope, these parents cited teaching the multiplication table (MT). According to these parents, MT can only be taught mostly through rote memorization using flash cards. Their concerns were similar to those expressed by Cohen, "Contrary to what American Romantics believed about learning, algebra and multiplication do not come naturally, even though they do come more easily to some than others.... The parallels in other practices may be useful here. Patients often enter behavior therapy, for instance, in order to cope with problems of overeating. ...it is probably less difficult to suppress overeating within a schedule of rewards and punishments than it is to probe personal history in order to locate the sources of gluttony, and, by understanding and working through, overcome them. Physical punishments and rewards may be painful, but responding to them requires less emotional and intellectual investment than deep and sustained self-examination" (Cohen, 1988, pp. 51-52). As in the argument presented by Cohen, some parents argued that some learning, like learning multiplication table, goes outside of the students' agency and, thus, different, non-agency, transmission of knowledge and memorization type of instruction is required.

However, some other parents, including me, disagreed and since I was responsible for math curriculum among parents, I volunteered (and was assigned) to develop a constructivist curriculum to teach multiplication for our mixed $1^{\text {st }}$ and $2^{\text {nd }}$ grade classroom (the school was based on mixed-grade classrooms). The parents decided to allow me to experiment to see if constructivist teaching of the multiplication table was possible. To be short and skip details, I came to an idea of giving children printouts of partially filled 12x12 multiplication tables with an assignment for the children to find as many patterns of filling out the multiplication table as possible (Matusov, 2001). The children were supposed to 
find new patterns of MT while filling out the numbers in the table and they presented the patterns to the adults who were supposed to record them on a classroom easel. My pedagogical goal at that time was to engage the children in discovering and critical reflecting on a network of multiplication patterns that would build the foundation of their understanding and embodied mnemonics for remembering multiplication as a by-product of these patterns. I hoped that the children's prolonged engagement in the numerous ways to fill out the table would require the children to discover the MT patterns and engage in critical dialogue of internally persuasive discourse about the MT. The children got immediately very excited with the assignment. Below, through several reconstructed vignettes, I want to show how children's self-generated critical authorship (i.e., the J-chronotope) emerged out of their responsive critical authorship (i.e., the DPchronotope).

\section{Vignette\#1 (emergent rich responsive autborship): Stealing patterns from a classmate}

A small group of students and two adult "co-opers" ${ }^{18}$ were sitting at a round table. The children chose to come to the activity that was advertised by me (one of the two co-opers) at the morning circle. The children had freedom to leave or join this activity at any time (there were other small group activities organized by several other adults or children might go to their own self-initiating activities or just browsing or wandering around the classroom). Although the time of the activity was limited to the mid-day recess break, children could continue this activity during or after the break or on another day or even at home, if they wished (see Rogoff, Turkanis, \& Bartlett, 2001, for a detailed enthographic description of the school).

Alex ${ }^{19}$ : Eugene (a parent responsible for math activities, the author), Lindsey stole my pattern!

Lindsey: $\quad$ Nah-ah! My pattern is different. Your pattern is adding by twos and my pattern is adding by threes and by fours. You've noticed only adding by twos, but l've noticed adding by whatever.

Paul (Alex's friend): But, Lindsey, it's the same. Adding by twos, by threes, by fours, by fives, by millions. It's the same. We shouldn't put it [Lindsey's pattern] on the list [of all MT patterns].

Mike (Lindsey's friend): No, it's different. Alex didn't know (that one can add) by threes, by fours, by fives, -- Lindsey discovered it. Alex was talking only about twos. Eugene, put Lindsey's pattern on the [MT] list.

Lindsey: You've noticed only adding by twos, but l've noticed adding by whatever.

Alex: $\quad$ You stole it. Without me, you'd have never noticed that!

Eugene (a parent, co-oper): This is an interesting thing. It sounds to me that both Alex and Lindsey have made big discoveries. Alex has noticed the first MT addition pattern. Lindsey has noticed a meta-pattern. "Meta" means "above" or "over" in Greek, I think. She has noticed a pattern of patterns. In Greek, it is called "meta", meta-pattern (Eugene put Lindsey's pattern on the MT list and marked it as 'meta-pattern'.)

Paul (repeats after Eugene): "A pattern of patterns."

Samantha (another parent in the classroom who eavesdropped on the conversation): I think that "meta" literally means something else, Eugene, but let me check the dictionary and report next week (when she would come again). It doesn't matter, though.

Jessica: Ah, l've also noticed a new meta-pattern. You can subtract not only by twos, as Mary has noticed, by also by threes, fours, and millions! Write it down, Eugene (Eugene wrote).

\footnotetext{
${ }^{18}$ This innovative public school required all parents contribute 3 hours per child per week, usually by designing and enacting learning activities. These parents were called "co-opers" (Rogoff, Bartlett, et al., 2001).

${ }^{19}$ All names of the parents, children, and teachers, except mine, are pseudonyms.
} 
Paul: $\quad$ There is not just one diagonal pattern, but many. It's also a meta-pattern.

Lindsey: $\quad$ 'Kids' is a meta-pattern for 'boys' and 'girls'. 'Tree' is a meta-pattern for 'leaves'.

Mike: $\quad$ And 'branches'.

Paul: $\quad$ Friendship is a meta-pattern of the MT.

Eugene: What? "Friendship"? How does it work? (Everyone looked at Paul with surprise.)

Paul: We do MT patterns and become friends. (Eugene wrote it on the MT list. Paul looked at the list). We need to check if the list already has other meta-patterns or we can develop new ones.

In my judgment, this vignette represents the emergence of very rich "runaway" responsive critical authorship by the participating children based on the DP-chronotope. The evidence of the students' authorship in response to the teacher's (i.e., parent's, Eugene's) original provocation to find MT patterns here is in the students' engagement in public evaluation and justification of each other's contributions deciding: 1) whether a proposed conjunction is a multiplication pattern (i.e., it predictably leads to the correct multiplication results) and 2) whether it is a truly new MT pattern that was not discovered previously by somebody else. The open-ended and multifaceted and multimedia nature of the assignment activity allows the children's creativity and as the vignette shows, the children committed to the creativity by searching for new MT patterns.

One can argue that there has been the presence of the self-generated critical authorship in this vignette when children started applying the notion of "meta" which emerged in Lindsey's pattern and was recognized by Eugene (me) - to non-mathematical objects. This was arguably a new self-assignment, which extended Eugene's original assignment to the point of being a new activity. I conservatively call it the proto self-generated authorship, because, as far as I know, this new self-assigned activity was shortlived and did not spread in the classroom, probably, because Eugene did not recognize and support it enough at that time.

The ontological space of DP-Chronotope is agora, a public forum and ontological time is unfolding critical dialogue initiated by the teacher (Eugene). Ontological axiology involves testing ideas. Ontological participation involves teacher-student negotiation. Didactic space is critical investigation of the Big and small cultures and practices. Didactic time involves dialogic provocations, bringing alternative ideas, and testing them. Didactic axiology involves dialogic and collective evaluation of ideas. Didactic participation involves diverse personal interests and interests emergent in dialogue.

Please notice that in this Dialogic Provocation Chronotope, the ontological and didactic aspects of the educational chronotope are in the transactional relationship with each other: the ontology and the didactics mutually constitute each other. This means that the emotional tensions in social relations among the participants (i.e., the ontology) reflect the tensions in their intellectual curricular ideas (i.e., the didactics). For example, the relational conflict between Alex and Lindsey about originality and plagiarism of their MT patterns (ontology) was solved through transformation of curricular ideas - i.e., introduction of the notion of "meta-pattern" by Eugene who recognized Lindsey's unique innovative contribution and distinguished her MT pattern from Alex's one (didactics). The ontology (e.g., relational conflict of accusation of stealing the original MT pattern) drives the didactics (e.g., discussion of "meta-patterns") by provoking the latter while the didactics (e.g., discussion of "meta-patterns) drives the ontology by resolving the former (e.g., the notion of meta-pattern helped to resolve a conflict around "stealing" Alex's MT pattern by Lindsey). The ontology and the didactics are united in the Dialogic Provocation Chronotope (DP-chronotope) rather than separate like in the Assignment Chronotope. In the classroom activity above guided by the DP-chronotope, the alienation of A-chronotope is impossible because the curriculum is not alienated from the students (and the teacher). It took me many years to recognize this 
property of the Dialogic Provocation Chronotope but as you see second grader Paul nicely formulated the transactional relation between the ontology and the didactics by saying that friendship is a meta-pattern of MT, "We do MT patterns and become friends."

In the following vignette, there is evidence of the students' emergent self-assignments and thus, the J-chronotope. In this innovative school, there was no assigned homework. However, sometimes children moved classroom learning projects outside of the classrooms to home because they were so interested in doing them (and sometimes they also refused to go outside for a recess because they were so busy working on their classroom projects) (Rogoff, Bartlett, et al., 2001). In my view, this constitutes evidence of self-assignment because the students took ownership of the project from the adult who might initially assign this project to them.

Please notice here that the $\mathrm{J}$-chronotope requires the legitimate free, non-assigned, assignmentfree, time-space that can be "wasted" by the students but can easily become a resource for the students' self-assignments and curricular journeys. Legitimate non-assigned time - free time for students that is solely decided by students of how to define and spend it - is an important component defining the espoused J-Chronotope. Rousseau reminded us, "May I venture at this point to state the greatest, the most important, the most useful rule of education? It is: Do not save time, but lose it" (Rousseau, 1979, p. 57). I wonder if this "spill out" nature of the teacher's promoted learning projects - that the project can be so exciting for the students that they can take them over to expand and transform their own projects - is an important part of the J-chronotope. However, I also wonder if the J-chronotope (i.e., purely Jchronotope) can emerge without its DP-chronotope precursor, when, for example, a students' learning cooperative invites a teacher to help them with an already established educational journey or do it completely on their own (see, for example, students' "clubs" and "corporations" in Democratic schools, Greenberg, 1992b; "learning circles" described by Mandela, 1995; or see description of learning in the "youth-based organizations", McLaughlin, Irby, \& Langman, 2001).

\section{Vignette\#2 (emergence of self-assignments): What is math pattern?}

First grade girl Aisha showed a small group of children and Eugene a finger pattern of multiplying of digits by nine that she learned from her older brother and asked Eugene to add it to the MT list. Aisha raised two hands with spreading all her 10 fingers. Then she demonstrated that if one wants to multiply 9 by 7 , the seventh finger has to be fold and the remaining 3 fingers on the right hand indicate the ending digit of the multiplication result: $9 \times 7=6 \underline{3}$ : six fingers on the left and right hands before the bended finger and 3 fingers on the right hand after bended finger. Aisha claimed that this pattern works for any multiplication by the number 9 . Second grade boy Harley objected:

Harley: It is not an MT pattern. You cannot write it down. You cannot see it in the (multiplication) table. It's just a finger rule.

Jessica: $\quad$ Yes, it is! It's something that repeats (as a pattern) and gives the right answers.

Harley: You don't see it. You don't know why it's. It's like magic, like a calculator. Magic isn't a pattern. Calculator isn't a pattern. You click, click, and get a right number. But it's NOT a pattern.

Aisha: Nah-ah!

[Silence. Impasse.]

Eugene: Raise your hand, if you think that a finger rule is an MT pattern. (Kids raised their hands. Eugene counted 3 pro and 4 against).

Aisha: You cannot vote on math.

Chris: Why not? We vote on many other things. 
Aisha: $\quad$ You think math, not vote.

Harley: I agree with Aisha. Eugene, we cannot vote on math. Even if all kids vote against $2+2=4$, it's still true.

Eugene: $\quad$ So, what should we do? How should we find out if the finger rule of multiplication by 9 is a math pattern or not?

Harley: We need to talk and think. Aisha, why do you think that your rule is a math pattern?

Aisha: I don't know (she sounds being upset, almost crying, her voice was breaking). (There is silence as the kids are thinking about the problem. Some were looking at the MT, some drew something in the air. Some repeating Aisha's manipulation with fingers. Chris was walking around in circles, putting his hands on his head. Suddenly,...).

Chris: I know! It's because when (multiplying) by nine, the last digit decreases by one! (Chris went in length describing that and connecting this discovery with the finger rule. The rest of the group, including Eugene, got very excited).

Jessica: Can we invent a finger rule for 8 ?

Harley: $\quad$ I'll think about it really hard. Maybe my mom will help me.

Aisha: We can think really hard together. We should tell this task to the whole class ${ }^{20}$. I also want to think really hard if there is an MT dance pattern. We can dance MT! (kids started dancing and laughing).

Samantha (another parent to Eugene): It's an interesting issue when we legitimately can and should vote and when we should not. I think we should discuss it with adults and kids. I'll take a note of this.

In my judgment, there is strong evidence for the full emergence of the J-chronotope here. Let me list at least four self-assignments that I see here. First, it was Aisha, who took the activity home and shared it with her older brother (and her parents). Second, it was a collective inquiry of how to evaluate if a MT pattern is mathematical in its nature. Third, it is a collective inquiry of finding mathematical understanding, if not a proof, behind each MT pattern. Finally, fourth, it was Samantha's (adult) inquiry of when voting is legitimate and when it is not. Although, these self-assignments were short-lived and did not lead to longterm projects, all four self-assignments affected the communal life in prolonged ways. Aisha seemed to model her self-assignment of taking the MT activity home to some children. Evaluation of the mathematical nature of patterns became a widespread activity in the classroom, children started searching for mathematical (and other) understanding of patterns (i.e., why they predictably lead to the correct answers), and the discussion of legitimate decision making and their limitations became a part of the community discourse (although among the community adults this issue had had some history and was well grounded ${ }^{21}$ ).

The emergence of the J-chronotope apparently requires relinquishing unilateral power from the teacher for the public space of communication (ontology) and defining the collective goal of the learning activity (didactics). The leading adult in charge had to recognize, validate, and promote emerging protoself-assignments and curriculum journeys while tabling, postponing, or canceling all together his own assignments. This is often a tough prospective for the leading adult in charge because of his or her fear of dissipation of the ontological focus (i.e., a collective focus on some unified topic) or the didactic focus (i.e., losing educational value of the activity) or even both (cf. Tharp \& Gallimore, 1988). In my view, the resolution of these real concerns, as the following vignette shows, lays in sharing the responsibility for the

\footnotetext{
${ }^{20}$ Later, Aisha shared the problem with the entire class and the children did develop multiplication patterns for all other digits (Matusov, 2001).

${ }^{21}$ During our parent meetings, the parents and the teachers discussed both importance and limitations of collaborative decisionmaking with and among the children (see, Matusov, 1999; Rogoff, Bartlett, et al., 2001, for more examples and discussion).
} 
community ontology and community didactics with the entire learning community that sets it on an educational long-term journey.

\section{Vignette\#3 (emergence of the curricular journey): Time and place to talk and think about math}

Two weeks after the events described in Vignette\#1, in the morning circle, the children shared their previous day home experiences and toys they brought from home. Suddenly, Alex raised his hand. When acknowledged by the teacher Annabelle, he started talking about a math pattern that he discussed with his dad at home:

Alex: I want to talk about a new meta-pattern that my dad and I discovered yesterday. Jessica: $\quad$ This is a sharing time. We share our toys. We do not talk about math.

Samantha (a parent): Alex, why don't you talk about your math pattern in Eugene's math group? Annabelle (the teacher): We haven't finished with Lindsey's presentation of her balancing bird yet. Alex: $\quad$ But I need to talk to whole class, not just to Eugene's group.

Annabelle, the teacher: Why don't we have the whole class for Eugene's math activity today?

Aisha: No, Alex is right. We need to talk about MT patterns in the sharing circle. Because. Sometimes we want to talk [about math patterns] and sometimes we don't. It was what happened with Alex yesterday. If he lost a tooth, he would talk [in the morning sharing circle]. If he found a new MT pattern or has a task for us, he should talk too.

Annabelle, the teacher: Hmm, interesting. Any other ideas? Raise your hand, if you want to speak up. (Many kids raised their hands. A girl raised her hand weaving it with passion, very eager to speak up). Mary.

Mary: We shouldn't talk about learning in the morning circle. Because [otherwise] we'd nothing to do after that.

Harley: I agree with Aisha. We need to think in small groups with Eugene and we need to talk in a circle. But if there's nothing to talk, we'll talk about toys and yesterday's experiences. (After more discussion, Annabelle asked the kids and adults to vote. Alex's suggestion passed by a large majority.)

In my analysis, this vignette presents the birth of the mathematical community, in which the participants develop math problems for each other and collectively solve them through a special public internally persuasive discourse (Bakhtin, 1991; Matusov, 2009a; Matusov \& von Duyke, 2010). This birth involves taking collective responsibility for the organization of the communal public space (ontology) - the morning circle and beyond - and the didactic space (e.g., "If he found a new MT pattern or has a task for us, he should talk too") and freedom to participate or not to participate, to have a math discussion or not to have it. The latter is crucially important for the J-chronotope and can be acutely troublesome as I will discuss below.

I have found it interesting that in order to illustrate a polyphonic learning dialogue I was forced to bring several vignettes rather than just one as in other types of classroom interaction (i.e., non-localized ontological and didactic time). In each of the three vignettes, new self-generated authorships have emerged through dialoguing with the other emerging authorships in the other vignettes. For example, in first vignette, Eugene's new authorship of a constructivist teacher who designs a new lesson of teaching the multiplication table in a constructivist way has emerged only through the emergence of the children's voices and new authorships and his (and the other adults') recognition of this phenomenon. His selfassignment is to provoke self-assignments of the students. Paradoxically, the students' self-assignments (e.g., friendship as a meta-pattern of MT, patterns of multiplication for other numbers than 9, dancing patterns of MT, redefining the morning circle) also promote each other and self-assignments in the adults 
(e.g., Samantha's consideration when voting is and is not appropriate decision making process). This is polyphony of self-generated critical authorship. The authorship was critical as the participants demanded taking responsibility for each other's transcendence through testing and replying on each other's ideas.

Like in the DP-chronotope discussed above, in the J-chronotope, there are mutually related processes of critical mathematization of the participants' social life and socialization of math practice (see, Lave, 1992). Math practice mediated the social relations and their transformation while social relations filled math practices with local and embedded meanings for the participants. However, I argue that in nonpolyphonic dialogue, these processes are responsive to the teacher's assignment-investigation and do not generate new authorial agencies, at least not in a full-blown way. In contrast, polyphonic dialogue generates new authorial agencies in the students around the practice of math (Brown \& Renshaw, 2000).

Cohen argues that the birthmark of any dialogic or polyphonic teaching (or what he called "adventurous teaching") is the participants' attraction to uncertainty,

Such work can be fascinating, and students could learn a great deal about mathematical reasoning ${ }^{22}$ from it. But in order to do so they would have to tolerate considerable uncertainty: about the nature of arithmetical problems; about the procedures for solving these problems; about what the answers are, and what an answer is; and about how implausible answers can be detected, and plausible answers defended. If done well, this would lead on to questions about the nature of arithmetic, and what it means to know it. That would be all to the good: If done carefully, such work can be immensely illuminating. But it requires that students find ways to embrace uncertainty, that they adopt trying out--that is, hypothesis framing and testing--as a way of life in learning. To do so, teachers and students must devise instructional strategies that enable them to manage and capitalize on the higher levels of uncertainty and the more demanding thought required to manage it. Such strategies are available, but they make unusual demands on teachers and students. They have been little investigated, but there is no evidence that they are easy (Cohen, 1988, p. 60).

Clearly, uncertainty is a part of the DP- and J-chronotope for teaching and learning because it heavily involves the internally persuasive discourse of critically testing and examining truths (Morson, 2004).

\section{The A-, DP-, and J-Chronotopes reconsidered}

Diverse educational foci generate diverse educational chronotopes. For example, as soon as a teacher (or a parent) sets a preset curricular endpoint as his or her educational goal, the espoused Achronotope will be activated as the consequence and it will acquire the educator, regardless of other ideological orientations of the teacher.

The espoused educational Assignment-Chronotope focuses on making all students achieve the preset curricular endpoints. A-Chronotope organizes conventional and some innovative education. In addition to curriculum, Conventional A-Chronotope also predefines instruction. In contrast, innovative AChronotope individualizes instruction while predefining curriculum. For example, Progressive education rooted in writings of Jean Jacques Rousseau (1979) and John Dewey (1956) arguably involves espoused A-Chronotope because Progressive education presets societal curriculum for students. Progressive education wants to "psychologize" the preset curricular endpoints (Dewey, 1956) to make the students

22 Incidentally, Cohen considers a hypothetical example of teaching multiplication table that is somewhat similar to what really occurred in the classroom I described. Unfortunately, Cohen did not develop specifics or visualizations of his example and it would be interesting to know if the reconstructed ethnography here fits and to what degree his ideas. I did not know about his pedagogical ideas until my colleague Katherine von Duyke pointed them to me when provided her feedback on an earlier version of my paper. 
want to learn what the society, usually represented by Progressive educational experts, wants them to learn. It actively tries to exploit and subjectize (using Foucault's term) student agency (cf. "educated subject", Fendler, 1998). While Dewey was apparently rather romantic about this exploitation, Rousseau seemed to be rather cynical,

Take the opposite course with your pupil [in child-centered, proto-Progressive, education that Rousseau advocated in contrast to a conventional authoritarian teacher-centered education -- EM]; let him always think he is master while you are really master. There is no subjection so completed as that which preserves the forms of freedom; it is thus that the will [of the child] itself is taken captive [by the teacher's hidden manipulation]. Is not this poor child, without knowledge, strength, or wisdom, entirely at your mercy? Are you not master of his whole environment so far as it affects him? Cannot you make of him what you please? His work and play, his pleasure and pain, are they not, unknown to him, under your control? No doubt he ought only to do what he wants, but he ought to want to do nothing but what you want him to do. He should never take a step you have not foreseen, nor utter a word you could not foretell (Rousseau, 1979, p. 120, italics are mine).

Psychologists supporting Progressive education (e.g., Rigby, Deci, Patrick, \& Ryan, 1992) try to develop notions like "internalized" or "identified" or "integrated" motivation to address the Holy Grail of Progressive Education: how to colonize student agency with a desire for their societal curriculum without student ever knowing about this colonization but rather believing that they freely accept it (see my detailed and nuanced critique of Progressive education in Matusov, 2015, submitted). If conventional monologic education tries to postpone the student authorial agency until the student is fully educated, Progressive education tries to colonize the student authorial agency with the educational societal desires (Matusov, von Duyke, \& Kayumova, 2015, submitted).

In Dialogic Pedagogy, curriculum - the space of the didactic chronotope - emerges in dialogue between the student and the Big Culture, the Culture of entire humanity in its past, present, and future (Bibler, 2009) - it is not preset. Dialogic Pedagogy aims at promoting student critical authorial agency and it is rooted in the student authorial agency. It is viewed as being for and from authorial agency (Matusov, Smith, Soslau, Marjanovic-Shane, \& von Duyke, 2015, submitted). The Dialogic Provocation Chronotope focuses on promoting responsive critical authorial agency in all students. Meanwhile, the educational Journey Chronotope focuses on promoting self-generated critical authorial agency in all students. There can be a tension between DP-Chronotope and J-Chronotope. The strongest side of the DP-Chronotope is its embeddedness into critical dialogue, which may come at expense of self-generated authorship (Matusov, 2011a). In contrast, the strongest side of the J-Chronotope is its self-generated authorship that may come at expense of being not very critical when a student's learning journey is outside of critical dialogue. That is why, I wonder if some kind of combination of DP- and J- Chronotopes, rather than exclusive reliance on only one of these chronotopes, is beneficial for Dialogic Pedagogy.

In the currently relatively small field of dialogic pedagogy, there is a debate about whether the goal of dialogic education should be to promote the responsive critical authorship in the students (what I call "narrow dialogic pedagogy") or to promote the self-generated critical authorship in the students (what I call "polyphonic pedagogy"). Should school produce an educated "reader of the Culture" based on the responsive critical authorship (narrow dialogic pedagogy) or an educated "writer of the Culture" based on the self-generated critical authorship (polyphonic pedagogy) in each student (see Berlyand, Kurganov, Osetinsky, Solomadin, Savvinykh, Author debate on a Russian electronic forum, June 2008, http://igorsolomadin.livejournal.com/40661.html?view=120533) (and see also, Bibler, 2009; Matusov, 2009b; Miyazaki, 2011)? In the narrow dialogic pedagogy, the student's authorship is seen as a response to the 
teacher's dialogic provocations and as moving the student into a Big Culture and a Big Critical Discourse. For the proponents of responsive critical authorship as the goal of education (i.e., student as "an educated, critical reader" of culture), the student's initial agency and areas of interests are often not validated as legitimate or may be even seen as disruptive and harmful, like watching TV, playing videogames, chatting on the Internet, playing (see this debate among Berlyand, Miyazaki, and Matusov in, Matusov, 2009b; Miyazaki, 2011). In contrast to the narrow dialogic pedagogy, the polyphonic pedagogy sees any student as an already capable author from the beginning, whose existing interests and areas of the authorship are legitimate and welcome in the classroom for expansion, critical deepening, and amendment (cf. Gee, 2003). But in any case, dialogic education in a broader sense is dialogic education for agency by focusing on promoting either responsive and/or self-generated critical authorship in the students. In dialogic education, teaching is authorial and learning is authorial (i.e., creative, improvisational, responsible, critical, unique, situational, ontologized, personal, immobile, phronêtic, agency- and voice-based). Meanwhile in the espoused A-chronotope of conventional pedagogy, teaching is instrumental and learning is instrumental (i.e., universal, decontextualized, deontologized, standardized, impersonal, mobile, technological, object- and tool-oriented) (for more detailed and nuanced discussion of authorial vs. instrumental/technological teaching/learning see, Matusov, 2011a).

The students' educational critical authorship can be achieved by providing "negative" and "positive" freedoms for the students (here I am using the terms coined by Berlin, 1969). The negative freedom involves setting opportunities - time, space, materials, model examples, provoking texts, and necessary guidance -- for the students to get inspired, develop, and pursue their own (individual and/or collective) self-assignments, educational journeys, and self-initiated activities: both emergent and preexisting. The positive freedom involves setting exciting educational activities and projects, which the students can join through clubs and activity centers (Matusov, 2009a, ch. 10). The negative and positive freedoms interact with each other: offered clubs and activity centers can spark the emergence of students' new self-assignments and educational journeys while the students' self-assignments and educational journeys recognized and supported by the teachers can create new clubs and activity centers for other students. In fact, recognizing, legitimatizing, validating, supporting, and extending through guidance ALL contributions by the students as important educational resources that have deep teachinglearning opportunities is one of the major tenets of dialogic pedagogy in a broad sense (Bibler, 2009; Osetinsky, 2009). Below is the table, where I put my current tentative ideas about educational espoused chronotopes together.

Table 1. Major espoused educational chronotopes

\begin{tabular}{|c|c|c|c|c|c|}
\hline \multirow{2}{*}{\multicolumn{2}{|c|}{ Chronotope aspect }} & \multicolumn{2}{|l|}{ A-Chronotope } & \multirow{3}{*}{$\begin{array}{l}\text { DP-Chronotope } \\
\text { Unfolding critical } \\
\text { dialogue initiated } \\
\text { by the teacher }\end{array}$} & \multirow{3}{*}{$\begin{array}{l}\text { J-Chronotope } \\
\\
\text { Project- } \\
\text { adventure }\end{array}$} \\
\hline & & \multirow[b]{2}{*}{$\begin{array}{l}\text { Conventional } \\
\text { Term assigned by } \\
\text { educational experts } \\
\text { (e.g., lesson, } \\
\text { semester, grade, } \\
\text { school) }\end{array}$} & \multirow[b]{2}{*}{$\begin{array}{l}\text { Progressive } \\
\text { Term assigned by } \\
\text { educational experts and } \\
\text { then psychologized by } \\
\text { the students }\end{array}$} & & \\
\hline \multirow{3}{*}{$\begin{array}{l}\text { Ontological } \\
\text { chronotope }\end{array}$} & Ontological time & & & & \\
\hline & $\begin{array}{l}\text { Ontological } \\
\text { space }\end{array}$ & $\begin{array}{l}\text { Sterile space } \\
\text { imposed by } \\
\text { educational experts } \\
\text { to channel students' } \\
\text { attention and restrict } \\
\text { movements (e.g., } \\
\text { classroom) }\end{array}$ & $\begin{array}{l}\text { Rich learning } \\
\text { environment designed } \\
\text { by educational experts } \\
\text { and then psychologized } \\
\text { by the students }\end{array}$ & $\begin{array}{l}\text { Agora, forum, } \\
\text { square, public } \\
\text { space for dialogue }\end{array}$ & $\begin{array}{l}\text { Life } \\
\text { environment }\end{array}$ \\
\hline & $\begin{array}{l}\text { Ontological } \\
\text { axiology }\end{array}$ & $\begin{array}{l}\text { Assigned and } \\
\text { imposed norms of } \\
\text { the society }\end{array}$ & $\begin{array}{l}\text { Assigned norms of the } \\
\text { society psychologized } \\
\text { by the students }\end{array}$ & $\begin{array}{l}\text { Teacher-student } \\
\text { dialogically } \\
\text { negotiated and } \\
\text { tested }\end{array}$ & $\begin{array}{l}\text { Self-judged, } \\
\text { self-tested, } \\
\text { self-assigned }\end{array}$ \\
\hline
\end{tabular}




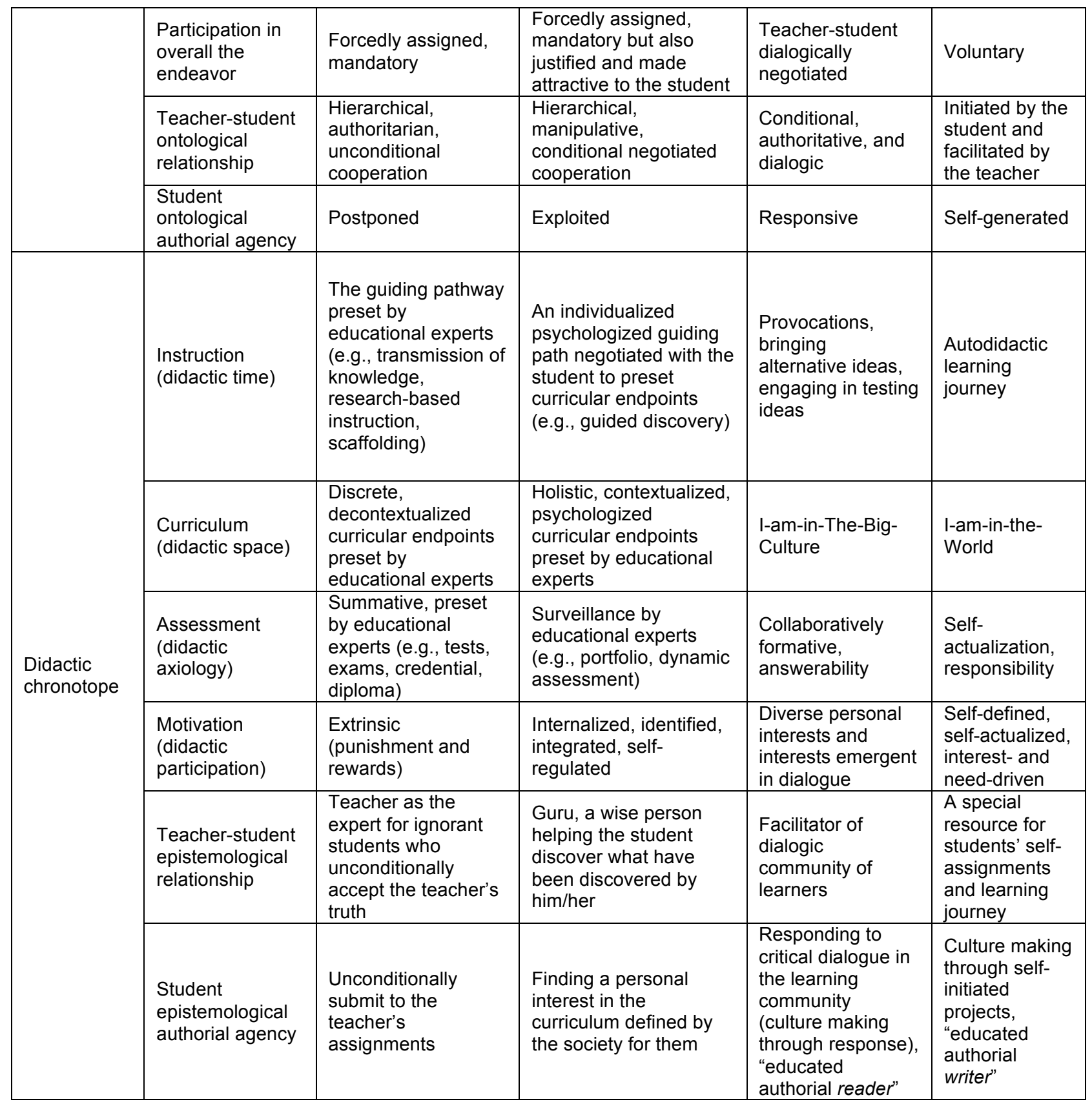

\section{Conclusion}

In this paper, I have discussed the three major espoused educational chronotopes:

1) the Assignment Chronotope, the most common in the conventional schools, focuses on making the students to arrive at the preset curricular endpoints;

2) the Dialogic Provocation Chronotope, which is based on narrowly defined dialogic pedagogy and involving promotion of the students' responsive critical authorship; and

3) the Journey Chronotope based on polyphonic dialogic pedagogy that focuses on promoting the 
students' self-assignments and self-initiated educational journeys that can propel self-generated critical authorship in a targeted practice (or a network of practices).

In A-Chronotope of conventional schools, time is lesson, space is classroom, axiology is summative assessment of mark grades, participation is forced, and relationship is unconditional cooperation with the teacher. In DP-Chronotope, time is responsive critical discussion testing ideas, desires, and values, space is space is the Big Culture - i.e., the culture of the entire humanity on all past, present, and future scales (Bibler, 1991), -- axiology is formative, participation is negotiated and constrained, and relationship is conditional collaboration with the teacher. In J-Chronotope, time is a learning journey, space is the World, axiology is self-actualization and contribution to the society, participation is voluntary and negotiated, and relationship is respectful of non-participation and non-cooperation with the teacher (see Table 1).

I argue that in the contrast to DP- and J-chronotopes, the espoused A-chronotope splits the ontological and didactic aspects of the educational chronotope and makes these aspects self-contained and independent of each other (although they can influence and interact with each other as independent entities). In the P- and J-chronotopes, the ontology and didactics mutually constitute each other even, as I argued above, in the required learning experiences (although the required learning experiences can jeopardize the unity of the ontology and didactics).

I have come to a conclusion that each of the educational chronotopes is defined by its generating goal that I call "teacher orientation". As soon as, the educator sets this particular educational goal for him or herself, the corresponding chronotope starts emerging, generating, and unfolding through the educator's consecutive decision making of how to promote and facilitate the accomplishment of this educational goal. For example, as soon as the teacher sets (i.e., rigidly prioritizes) his or her educational goal by requiring students to arrive at some particular preset curricular endpoints, the espoused Achronotope (and, thus, a type of monologic pedagogy ${ }^{23}$ ) will emerge: the ontology and the didactics will spilt in the teaching curriculum, assignments will be designed, the learning activities will become purified, a punitive grading system based on summative assessment starts developing and so on. Similarly, as soon as the teacher decides to focus on listening to the students' subjectivities, the DP-chronotope will emerge with its series of curricular provocations based on exposing the students to alternative ideas, values, and perspectives. There has been a debate in educational literature (e.g., Delpit, 1993) about whether authoritarian, monologic, education promoted by A-chronotope may be better than dialogic pedagogy for some students based on social class (e.g., working class) or culture (e.g., so-called "Asian" culture). In my view, the key issue is "better" for what? For socialization in existing practices and institutions, for getting access to colleges, for getting high test scores, for engaging students in critical exploration of what is good for them, and so on.

However, if the teacher prioritizes the students' self-generated critical authorship, the Jchronotope will emerge with its afterschool clubs of students' choices (Matusov, 2009a), the teacher's suggestions (rather than requirements) (Rancière, 1991), free-choice learning environment (Falk \& Dierking, 2002), "free schools" (Greenberg, 1992a, 1992b; Holt, 1972; Neill, 1960; Rietmulder, 2009), promotion of students' self-government and self-initiated activities and projects. In my judgment, the espoused A-chronotope is supported by conventional school institutional constraints and Western cultural traditions regarding what good guidance is about (de Haan, 1999; Rogoff, 2003). I hypothesize that these generating goals define the teacher's theory-in-action (Argyris \& Schön, 1978). Their espoused theories involving ideologies of educational philosophies might be irrelevant for the actual practice or reflecting the

\footnotetext{
${ }^{23}$ In my view, it is not by chance that Bakhtin (1999) used pedagogical examples for illustrate extreme cases of excessive monologism.
} 
teacher's struggle with their practice (i.e., wanting one thing but doing another thing). But this issue requires further investigation as well as ontological circumstances that support or hinder the diverse educational chronotopes. More sociocultural analysis of these chronotopes is needed: how institutions, cultures, power structure, economy, gender, and so on shape them and how these chronotopes shape these sociocultural aspects of human life. Also, critique and limitations of the DP- and J-chronotopes are needed as well in future both conceptual and empirical analysis. Finally, search for other, alternative, possible educational chronotopes can be helpful.

Saying all that about generative goal jumpstarting an in-use pedagogical chronotope of teaching, I want to emphasize that an espoused particular pedagogical chronotope promoted by a teacher does not fully determine the nature of learning experiences by the students due to students' activism, the teacher's inconsistences, and emergent property of discourse. As Sidorkin puts it and I agree with him, "No rules can guarantee that dialogue really happens, and dialogue may occur despite gravely monological forms of communication. Once dialogue begins, no one can channel it, or manage it, or transform it, even for the noble aims of education" (Sidorkin, 1999, p. 15). However, I argue that an espoused A-chronotope makes emergence of dialogic pedagogy more difficult than espoused DP- and J-chronotopes as the latter facilitate (albeit never guarantee) dialogic pedagogy.

The three major espoused educational chronotopes described in the paper are not the only possible scenarios. Not only there is diversity inside of these three generic chronotopes (e.g., Achronotope diversity: conventional education with preset curriculum and instruction vs. Progressive education with preset curriculum and individualized psychologized instruction), but I am sure that there are more than 3 generic chronotopes. Also, a teacher can have a mixture of espoused educational chronotopes while developing a complex and probably not very stable hybrid. This educational chronotopic diversity - both espoused and in-use — is worth of studying.

Currently, institutes of conventional schools have been organized to support the espoused Achronotope because this chronotope serves well standards-based, skill-based, and knowledge-based modern economy, state bureaucracy, and prevalent public desires. However, like some observers, I see the beginning of a painful transition to agency-based economy and society through increasing prevalence computerization, robotization, telecommunication, and outsourcing both blue and white collar standardsbased labor (Kaku, 2011; Pink, 2009; Zhao, 2009). May be I am too optimistic, but I see the recent US neo-liberal educational policy like Bush's "No Child Left Behind" and Obama's "Race To the Top" as last, but very painful, kicks of dying horse.

Finally, recently several scholars (Kukathas, 2003; Matusov \& Marjanovic-Shane, 2015, submitted) challenge the educational value of critical dialogue rooted in Ancient Greek questionable assumption that "unexamined life is not worth living" (Plato, 1997). In some cases, unexamined life is worth living and examined life is not worth living. Thus, we could ask whether "promoting authorial agency rooted in critical dialogue" - the goal of Dialogic Pedagogy - represents a preset curricular endpoint in itself? My colleague and I (Matusov \& Marjanovic-Shane, 2012) try to address this important issue by introducing the notion education as praxis of praxis ${ }^{24}$, according to which education differs from other practices by engaging students in investigating whether and what education is good for them. More investigation of this important issue is needed.

\footnotetext{
${ }^{24}$ This notion is based on the conceptual opposition introduced by Aristotle (2000). Aristotle introduced the notions of poïesis - a practice, which goal, quality, and definition are predefined before the process of the practice, in advance, - and praxis - a practice, which goal, quality, and definition emerge in the practice itself. Currently, with the standards-based reform movement, education is viewed as poïesis.
} 


\section{References}

Adler, M. J. (1982). The Paideia proposal: An educational manifesto (1st Macmillan paperbacks ed.). New York: Macmillan.

Alexander, P. A. (2005). The path to competence: A lifespan developmental perspective on reading. Journal of Literacy Research, 37(4), 413-436. doi: http://dx.doi.org/10.1207/s15548430jlr3704_1

Altman, I., \& Rogoff, B. (1987). World views in psychology: Trait, interactional, organismic, and transactional perspectives. In I. Altman \& D. Stokols (Eds.), Handbook of environmental psychology (pp. 613-627). New York: Wiley.

Argyris, C., \& Schön, D. A. (1978). Organizational learning: A theory of action perspective. Reading, MA: Addison-Wesley Pub. Co.

Aristotle. (2000). Nicomachean ethics (R. Crisp, Trans.). Cambridge, UK: Cambridge University Press.

Asimov, I. (1959). Profession. In I. Asimov (Ed.), Nine tomorrows: Tales of the near future ([1st ed., pp. 17-74). Garden City, NY: Doubleday.

Bakhtin, M. M. (1986). Speech genres and other late essays. Austin: University of Texas Press.

Bakhtin, M. M. (1990). Art and answerability: Early philosophical essays (V. Liapunov, Trans. 1st ed.). Austin: University of Texas Press.

Bakhtin, M. M. (1991). Dialogic imagination: Four essays by M. M. Bakhtin (C. Emerson \& M. Holquist, Trans.). Austin, TX: University of Texas Press.

Bakhtin, M. M. (1993). Toward a philosophy of the act (1st ed.). Austin: University of Texas Press.

Bakhtin, M. M. (1999). Problems of Dostoevsky's poetics (Vol. 8). Minneapolis: University of Minnesota Press.

Beach, K. D. (1999). Consequential transitions: A sociocultural expedition beyond transfer in education. Review of Research in Education, 24, 101-139.

Berlin, I. (1969). Four essays on liberty. London, New York [etc.]: Oxford University P.

Bettelheim, B. (1960). The informed heart: Autonomy in a mass age. Glencoe, IL: Free Press.

Bibler, V. S. (1991). Михаил Михайлович Бахтин или поэтика культуры (Mikhail Mikhailovich Bakhtin or the poetics of culture). Moscow: Progress.

Bibler, V. S. (2009). The foundations of the School of the Dialogue of Cultures Program. Journal of Russian \& East European Psychology, 47(1), 34-60. doi: http://dx.doi.org/10.2753/RPO10610405470102

Bloome, D., \& Katz, L. (1997). Literacy as social practice and classroom chronotopes. Reading \& Writing Quarterly, 13(3), 205-225.

Brandes, A. A. (1996). Children's image of science and gender. In Y. B. Kafai \& M. Resnick (Eds.), Constructionism in practice: Designing, thinking, and learning in a digital world (pp. 37-69). Mahwah, N.J.: Lawrence Erlbaum Associates.

Brown, R., \& Renshaw, P. (2000). Collective argumentation: A sociocultural approach to reframing classroom teaching and learning In H. Cowie \& G. Van der Aalsvoort (Eds.), Social interaction in learning and instruction: The meaning of discourse for the construction of knowledge (1st ed., pp. 52-66). New York: Pergamon. 
Cohen, D. K. (1988). Teaching practice: Plus Ça change... In P. W. Jackson (Ed.), Contributing to educational change: Perspectives on research and practice (pp. 27-84). Berkeley, CA: McCutchan Pub. Corp.

de Haan, M. (1999). Learning as cultural practice: How children learn in a Mexican Mazahua community. Amsterdam: Thela Thesis.

Delpit, L. D. (1993). The silenced dialogue: Power and pedagogy in educating other people's children. In L. Weis \& M. Fine (Eds.), Beyond silenced voices: Class, race, and gender in United States schools. (pp. 119-139). Albany, NY, US: State University of New York Press.

DePalma, R., Matusov, E., \& Smith, M. P. (2009). Smuggling authentic learning into the school context: Transitioning from an innovative elementary to a conventional high school. Teacher College Record, 111(4), 934-972.

Dewey, J. (1956). The child and the curriculum and the school and society (Combined ed.). Chicago: University of Chicago Press.

Eckert, P. (1989). Jocks and burnouts: Social categories and identity in the high school. New York: Teachers College Press.

Falk, J. H., \& Dierking, L. D. (2002). Lessons without limit: How free-choice learning is transforming education. Walnut Creek, CA: AltaMira Press.

Fecho, B. (2011). Writing in the dialogical classroom: Students and teachers responding to the texts of their lives. Urbana, IL: National Council of Teachers of English.

Fendler, L. (1998). What is it impossible to think? A genealogy of the educated subject. In T. S. Popkewitz \& M. Brennan (Eds.), Foucault's challenge: Discourse, knowledge, and power in education (pp. 39-63). New York: Teachers College Press.

Freire, P. (1986). Pedagogy of the oppressed. New York: Continuum.

Fromm, E. (1969). Escape from freedom. New York,: Avon Books.

Gee, J. P. (2003). What video games have to teach us about learning and literacy (1st ed.). New York: Palgrave Macmillan.

Gibson, E. J., \& Pick, A. D. (2000). An ecological approach to perceptual learning and development. Oxford, UK: Oxford University Press.

Greenberg, D. (1992a). The birth of a new paradigm for education. Retrieved from http://www.sudval.com/05_underlyingideas.html\#05

Greenberg, D. (1992b). The Sudbury Valley School experience. Framingham, MA: Sudbury Valley School Press.

Greeno, J. G. (1997). On claims that answer the wrong questions. Educational Researcher, 26(1), 5-17.

Hart, P. D. (2006). Report findings: Based on a survey among California ninth and tenth graders. Retrieved from http://www.connectedcalifornia.org/downloads/irvine_poll.pdf

Hidi, S., \& Renninger, K. A. (2006). The four-phase model of interest development. Educational Psychologist, 41(2), 111-127.

Holt, J. C. (1972). Freedom and beyond ([1st ed.). New York: E. P. Dutton.

Hunter, M. C. (1971). Teach for transfer. Thousand Oaks, California: Corwin Press. 
Hutchins, E. (1995). Cognition in the wild. Cambridge, Mass.: MIT Press.

Jackson, P. W. (1968). Life in classrooms. New York: Holt Rinehart and Winston.

Jensen, V. S. (2009). Into the marginal zone -- An autoethnographic journey through teaching experience. Master Thesis in Philosophy of Education, University of Bergen, Bergen, Norway.

Jones, R. (1972). The Third Wave, 1967, an account - Ron Jones. Retrieved from Libcom.org website: http://libcom.org/history/the-third-wave-1967-account-ron-jones

Kaku, M. (2011). Physics of the future: How science will shape human destiny and our daily lives by the year 2100 (1st ed.). New York: Doubleday.

Kennedy, M. M. (2005). Inside teaching: How classroom life undermines reform. Cambridge, MA: Harvard University Press.

Kohn, A. (2014). The myth of the spoiled child: Challenging the conventional wisdom about children and parenting. Boston, MA: Da Capo Lifelong.

Kotek, J., \& Rigoulot, P. (2000). Le siècle des camps: Détention, concentration, extermination, cent ans de mal radical. Paris: Lattès.

Kukathas, C. (2003). The liberal archipelago: A theory of diversity and freedom. Oxford: Oxford University Press.

Labaree, D. F. (1997). How to succeed in school without really learning: The credentials race in American education. New Haven, CT: Yale University Press.

Lampert, M. (2001). Teaching problems and the problems of teaching. New Haven: Yale University Press.

Latour, B. (1987). Science in action: How to follow scientists and engineers through society. Cambridge, MA: Harvard University Press.

Lave, J. (1988). Cognition in practice: Mind, mathematics, and culture in everyday life. Cambridge, UK: Cambridge University Press.

Lave, J. (1992). Word problems: A microcosm of theories of learning. In P. Light \& G. Butterworth (Eds.), Context and cognition: Ways of learning and knowing. (pp. 74-92). Hillsdale, NJ: Lawrence Erlbaum Associates, Inc.

Lave, J. (1992, April). Learning as participation in communities of practice. Paper presented at the meeting of the American Educational Research Association, San Francisco, CA.

Leander, K. M., \& Sheehy, M. (2004). Spatializing literacy research and practice. New York: P. Lang.

Lobok, A. (2001). The probabilistic world: The chronicles of the philosophical-pedagogical reflections of an educational experiment. Yekaterinoburg, Russia: Association of Small Businesses.

Mandela, N. (1995). Long walk to freedom: The autobiography of Nelson Mandela. London: Abacus.

Matusov, E. (1999). How does a community of learners maintain itself? Ecology of an innovative school. Anthropology \& Education Quarterly, 30(2), 161-186. doi:

http://dx.doi.org/10.1525/aeq.1999.30.2.161

Matusov, E. (2001). Becoming an adult member in a community of learners. In B. Rogoff, C. G. Turkanis \& L. Bartlett (Eds.), Learning together: Children and adults in a school community (pp. 166-174). New York: Oxford University Press. 
Matusov, E. (2007). Applying Bakhtin scholarship on discourse in education: A critical review essay. Educational Theory, 57(2), 215-237. doi: http://dx.doi.org/10.1111/j.1741-5446.2007.00253.x

Matusov, E. (2008). Dialogue with cultural-historical Vygotskian colleagues about a sociocultural approach. Culture \& Psychology, 14(1), 81-93.

Matusov, E. (2009a). Journey into dialogic pedagogy. Hauppauge, NY: Nova Science Publishers.

Matusov, E. (2009b). The School of the Dialogue of Cultures pedagogical movement in Ukraine and Russia. Journal of Russian \& East European Psychology, 47(1), 3-19.

Matusov, E. (2011a). Authorial teaching and learning. In E. J. White \& M. Peters (Eds.), Bakhtinian pedagogy: Opportunities and challenges for research, policy and practice in education across the globe (pp. 21-46). New York: Peter Lang Publishers.

Matusov, E. (2011b). Imagining 'No Child Left Behind' being freed from neoliberal hijackers. Democracy and Education, 19(2), 1-8. Retrieved from http://democracyeducationjournal.org/cgi/viewcontent.cgi?article=1016\&context=home

Matusov, E. (2015, submitted). Legitimacy of non-negotiable imposition in diverse approaches to education. Dialogic Pedagogy: An International Online Journal.

Matusov, E., \& Brobst, J. (2013). Radical experiment in dialogic pedagogy in higher education and its centaur failure: Chronotopic analysis. Hauppauge, NY: Nova Science Publishers.

Matusov, E., \& Marjanovic-Shane, A. (2012). Diverse approaches to education: Alienated learning, closed and open participatory socialization, and critical dialogue. Human Development, 55(3), 159-166. doi: 10.1159/000339594

Matusov, E., \& Marjanovic-Shane, A. (2015, submitted). The State's Educational Neutrality: Radical proposal for educational pluralism. Democracy and Education.

Matusov, E., Smith, M. P., Soslau, E., Marjanovic-Shane, A., \& von Duyke, K. (2015, submitted). Dialogic eduction from and for authorial agency. Outlines: Critical Social Studies.

Matusov, E., \& von Duyke, K. (2010). Bakhtin's notion of the Internally Persuasive Discourse in education: Internal to what? (A case of discussion of issues of foul language in teacher education). In K. Junefelt \& P. Nordin (Eds.), Proceedings from the Second International Interdisciplinary Conference on perspectives and limits of dialogism in Mikhail Bakhtin Stockholm University, Sweden June 3-5, 2009 (pp. 174-199). Stockholm: Stockholm University.

Matusov, E., von Duyke, K., \& Kayumova, S. (2015, submitted). Mapping concepts of agency in educational contexts. Dialogic Pedagogy: An International Online Journal.

McLaughlin, M. W., Irby, M. A., \& Langman, J. (2001). Urban sanctuaries: Neighborhood organizations in the lives and futures of inner-city youth (1st pbk. ed.). San Francisco: Jossey-Bass.

McNeil, L. M. (1986). Contradictions of control: School structure and school knowledge. New York: Routledge \& K. Paul.

Mercer, N., \& Littleton, K. (2007). Dialogue and the development of children's thinking: A sociocultural approach. London: Routledge.

Mitra, S. (2013). Build a school in the cloud. Retrieved from http://www.ted.com/talks/sugata_mitra_build_a_school_in_the_cloud 
Miyazaki, K. (2011). Encountering another dialogic pedagogy. Journal of Russian \& East European Psychology, 49(2), 36-43.

Morson, G. S. (2004). The process of ideological becoming. In A. F. Ball \& S. W. Freedman (Eds.), Bakhtinian perspectives on language, literacy, and learning (pp. 317-331). Cambridge, UK; New York: Cambridge University Press.

Morson, G. S. (2011). The worlds of others. Journal of Russian \& East European Psychology, 49(2), 6-15.

Morson, G. S., \& Emerson, C. (1990). Mikhail Bakhtin: Creation of a prosaics. Stanford, CA: Stanford University Press.

Neill, A. S. (1960). Summerhill: A radical approach to child rearing. New York: Hart Publishing Company.

Nystrand, M. (1997). Opening dialogue: Understanding the dynamics of language and learning in the English classroom. New York: Teachers College Press.

Osetinsky, V. (2009). Reading and literature in the primary and middle Schools of the Dialogue of Cultures. Journal of Russian \& East European Psychology, 47(2), 59-80.

Parker, M. (2001). The problem of transfer, and the sociocultural critique of schooling. Journal of the Learning Sciences, 10(4), 493-514.

Pink, D. H. (2009). Drive: The surprising truth about what motivates us. New York: Riverhead Books.

Plato. (1997). Complete works (J. M. Cooper \& D. S. Hutchinson, Trans.). Indianapolis, IN: Hackett Pub.

Plato, \& Bluck, R. S. (1961). Meno. Cambridge, UK: University Press.

Rancière, J. (1991). The ignorant schoolmaster: Five lessons in intellectual emancipation (K. Ross, Trans.). Stanford, CA: Stanford University Press.

Ravitch, D. (2007, February 25). Challenges to teacher education: Address to AACTE. Retrieved from http://groups.yahoo.com/group/nyceducationnews/message/2086

Reich, R. B. (1992). The work of nations: Preparing ourselves for 21st century capitalism (1st Vintage Books ed.). New York: Vintage Books.

Reich, R. B. (2001). The future of success (1st ed.). New York: A. Knopf.

Renshaw, P. D. (2007). A commentary on the chronotopes of different 'cultures of learning': Transforming classrooms from trading-places into relational-places of learning. International Journal of Educational Research, 46(3-4), 240-245.

Renshaw, P. D. (2013). Classroom chronotopes privileged by contemporary educational policy: teaching and learning in testing times. In S. Phillipson, K. Y. L. Ku \& S. N. Phillipson (Eds.), Constructing educational achievement: A sociocultural perspective (pp. 57-69). Oxon, UK: Routledge.

Rietmulder, J. (2009). The Circle School: An introduction to integral education ideas and practices. Harrisburg PA: The Circle School.

Rigby, C. S., Deci, E. L., Patrick, B. C., \& Ryan, R. M. (1992). Beyond the intrinsic-extrinsic dichotomy: Self-determination in motivation and learning. Motivation and Emotion, 16(3), 165-185.

Rogoff, B. (2003). The cultural nature of human development. New York: Oxford University Press.

Rogoff, B., Bartlett, L., \& Goodman Turkanis, C. (2001). Lessons about learning as a community. In B. Rogoff, C. G. Turkanis \& et al. (Eds.), Learning together: Children and adults in a school community. New York: Oxford University Press. 
Rogoff, B., Turkanis, C. G., \& Bartlett, L. (Eds.). (2001). Learning together: Children and adults in a school community. New York: Oxford University Press.

Rousseau, J. J. (1979). Emile: or, On education. New York: Basic Books.

Scribner, S., \& Cole, M. (1981). The psychology of literacy. Cambridge, MA: Harvard University Press.

Sidorkin, A. M. (1999). Beyond discourse: Education, the self, and dialogue. Albany, NY: State University of New York Press.

Sidorkin, A. M. (2002). Learning relations: Impure education, deschooled schools, \& dialogue with evil. New York: P. Lang.

Sidorkin, A. M. (2009). Labor of learning: Market and the next generation of education reform. Rotterdam, the Netherlands: Sense Publishers.

Smith, F. (1985). A metaphor for literacy: Creating worlds or shunting information? In D. R. Olson, N. Torrance \& A. Hildyard (Eds.), Literacy, language, and learning: The nature and consequences of reading and writing (pp. 195-213). New York: Cambridge University Press.

Smith, M. P. (2010). The parallel discursive universes of teachers and students. PhD Doctoral Dissertation, University of Delaware, Newark, DE.

Solomadin, I., \& Kurganov, S. Y. (2009). The history of World Culture as Dialogue of Cultures middle and high school curricula. Journal of Russian \& East European Psychology, 47(2), 3-29.

Taubman, P. M. (2009). Teaching by numbers: Deconstructing the discourse of standards and accountability in education. New York: Routledge.

Tharp, R. G., \& Gallimore, R. (1988). Rousing minds to life: Teaching, learning, and schooling in social context. Cambridge, New York: Cambridge University Press.

Varenne, H., \& McDermott, R. P. (1998). Successful failure: The school America builds. Boulder, CO: Westview Press.

Waller, W. W. (1932). The sociology of teaching. New York: J. Wiley \& sons.

Wegerif, R. (2007). Dialogic, educational and technology: Expanding the space of learning. New York: Springer-Verlag.

Wenger, E. (1998). Communities of practice: Learning, meaning, and identity. Cambridge, UK: Cambridge University Press.

White, E. J. (2013). Circles, borders and chronotope: Education at the boundary. Knowledge Cultures, $1(2), 145-169$.

Whitson, J. A. (2007). Education à la Silhouette: The need for semiotically-informed curriculum consciousness. Semiotica, 164(1/4), 235-329.

Willis, P. E. (1981). Learning to labor: How working class kids get working class jobs (Morningside ed.). New York: Columbia University Press.

Yazzie-Mintz, E. (2006). Voices of students on engagement: A report on the 2006 High School survey of student engagement. Retrieved from http://letsgetengaged.wikispaces.com/file/view/HSSSE_2006_Report.pdf

Zhao, Y. (2009). Catching up or leading the way: American education in the age of globalization. Alexandria, VA: ASCD. 


\section{(cc) EY}

New articles in this journal are licensed under a Creative Commons Attribution 4.0 United States License.

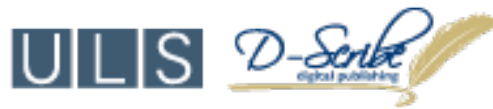

This journal is published by the University Library System, University of Pittsburgh as part of its D-Scribe Digital Publishing Program and is cosponsored by the University of Pittsburgh Press. 